\title{
Identification of Brain-Specific Treatment Effects in NPC1 Disease by Focusing on Cellular and Molecular Changes of Sphingosine-1-Phosphate Metabolism
}

\author{
Anne Gläser ${ }^{1,2}{ }^{,}$Franziska Hammerl $^{1}$, Markus H. Gräler ${ }^{3}{ }^{\circledR}$, Sina M. Coldewey ${ }^{4}$, \\ Christin Völkner ${ }^{5}$, Moritz J. Frech ${ }^{5,6}{ }^{\mathbb{D}}$, Fan Yang ${ }^{5}$, Jiankai Luo ${ }^{5,6}$, Eric Tönnies ${ }^{7}$, \\ Oliver von Bohlen und Halbach ${ }^{7}$ (D) Nicola Brandt ${ }^{1}$, Diana Heimes ${ }^{2}$, Anna-Maria Neßlauer ${ }^{2}$, \\ Georg Christoph Korenke ${ }^{8}$, Marta Owczarek-Lipska 9,10, John Neidhardt 9,11, Arndt Rolfs ${ }^{12}$, \\ Andreas Wree ${ }^{2}$, Martin Witt ${ }^{2}$ (D) and Anja Ursula Bräuer 1,2,11,*(D) \\ 1 Research Group Anatomy, School of Medicine and Health Sciences, Carl von Ossietzky University \\ Oldenburg, 26129 Oldenburg, Germany; anne.glaeser@uni-oldenburg.de (A.G.); \\ franziska.hammerl@uni-oldeburg.de (F.H.); nicola.brandt@uni-oldenburg.de (N.B.) \\ 2 Institute of Anatomy, Rostock University Medical Center, 18057 Rostock, Germany; \\ dianaheimes@web.de (D.H.); anna-maria.nesslauer@uni-rostock.de (A.-M.N.); \\ andreas.wree@med.uni-rostock.de (A.W.); martin.witt@med.uni-rostock.de (M.W.) \\ 3 Department of Anaesthesiology and Intensive Care Medicine, Center for Sepsis Control and Care (CSCC), \\ Center for Molecular Biomedicine (CMB), Jena University Hospital, 07745 Jena, Germany; \\ markus.graeler@med.uni-jena.de \\ 4 Department of Anaesthesiology and Intensive Care Medicine, Septomics Research Center, Center for Sepsis \\ Control and Care, Jena University Hospital, 07747 Jena, Germany; sina.coldewey@med.uni-jena.de \\ 5 Translational Neurodegeneration Section "Albrecht Kossel”, Department of Neurology, University Medical \\ Center Rostock, University of Rostock, 18147 Rostock, Germany; \\ christin.voelkner@med.uni-rostock.de (C.V.); moritz.frech@med.uni-rostock.de (M.J.F.); \\ timyang14@hotmail.com (F.Y.); Jiankai.luo@uni-rostock.de (J.L.) \\ 6 Center for Transdisciplinary Neurosciences Rostock (CTNR), Rostock University Medical Center, University \\ of Rostock, 18147 Rostock, Germany \\ 7 Institute of Anatomy and Cell Biology, University Medicine Greifswald, 17487 Greifswald, Germany; \\ eric.toennies@med.uni-greifswald.de (E.T.); oliver.vonbohlen@uni-greifswald.de (O.v.B.u.H.) \\ 8 Department of Pediatrics, Klinikum Oldenburg, 26133 Oldenburg, Germany; \\ korenke.christoph@klinikum-oldenburg.de \\ 9 Human Genetics, School of Medicine and Health Sciences, University of Oldenburg, \\ 26129 Oldenburg, Germany; marta.owczarek-lipska@uni-oldenburg.de (M.O.-L.); \\ john.neidhardt@uni-oldenburg.de (J.N.) \\ 10 Junior Research Group, Genetics of childhood brain malformations, School of Medicine and Health Sciences, \\ University of Oldenburg, 26129 Oldenburg, Germany \\ 11 Research Center for Neurosensory Science, Carl von Ossietzky University Oldenburg, \\ 26129 Oldenburg, Germany \\ 12 Centogene AG, D-18055 Rostock, Germany; arndt.rolfs@centogene.com \\ * Correspondence: anja.braeuer@uni-oldenburg.de; Tel.: +49-441-798-3995
}

Received: 10 June 2020; Accepted: 21 June 2020; Published: 24 June 2020

check for updates

\begin{abstract}
Niemann-Pick type C1 (NPC1) is a lysosomal storage disorder, inherited as an autosomal-recessive trait. Mutations in the Npc1 gene result in malfunction of the NPC1 protein, leading to an accumulation of unesterified cholesterol and glycosphingolipids. Beside visceral symptoms like hepatosplenomegaly, severe neurological symptoms such as ataxia occur. Here, we analyzed the sphingosine-1-phosphate (S1P)/S1P receptor (S1PR) axis in different brain regions of $\mathrm{Npc1}^{-/-}$mice and evaluated specific effects of treatment with 2-hydroxypropyl- $\beta$-cyclodextrin $(\mathrm{HP} \beta \mathrm{CD})$ together with the iminosugar miglustat. Using high-performance thin-layer chromatography (HPTLC), mass spectrometry, quantitative real-time PCR (qRT-PCR) and western blot analyses, we
\end{abstract}


studied lipid metabolism in an NPC1 mouse model and human skin fibroblasts. Lipid analyses showed disrupted S1P metabolism in $\mathrm{Npc}^{-/-}$mice in all brain regions, together with distinct changes in S1pr3/S1PR3 and S1pr5/S1PR5 expression. Brains of $\mathrm{Npc1}^{-/-}$mice showed only weak treatment effects. However, side effects of the treatment were observed in $\mathrm{Npc1}^{+/+}$mice. The S1P/S1PR axis seems to be involved in NPC1 pathology, showing only weak treatment effects in mouse brain. S1pr expression appears to be affected in human fibroblasts, induced pluripotent stem cells (iPSCs)-derived neural progenitor and neuronal differentiated cells. Nevertheless, treatment-induced side effects make examination of further treatment strategies indispensable.

Keywords: Niemann-Pick disease type C1; brain; fibroblasts; S1P; sphingosine-1-phosphate receptors; qRT-PCR; sphingolipids; HPTLC; mass spectrometry; white matter

\section{Introduction}

Niemann-Pick disease type C1 (NPC1) is a rare autosomal-recessive lipid storage disease, which is caused by mutations in the Npc1 gene ( $95 \%$ of the patients) [1,2]. It encodes for the transmembrane protein NPC1, found in late endosomes, that is suggested to be involved in the intracellular translocation of unesterified cholesterol to other cytoplasmic cell compartments [3,4]. Mutations result in impaired lipid trafficking, characterized by neurovisceral accumulation of unesterified cholesterol and glycosphingolipids, sphingosine (Sph), gangliosides (GM2, GM3) and other fatty acids in the endosomal/lysosomal system (LE/LY) [5-7]. This results in a heterogeneous, multisystemic spectrum of symptoms, such as extensive loss of Purkinje cells in the cerebellum (CE) and a variety of progressive neurological and visceral symptoms, such as ataxia, dystonia, dysphagia, psychiatric problems and hepatosplenomegaly as one of the first symptoms occurring [8-14].

The age of onset ranges from early infancy to an adolescent/adult onset corresponding to the estimated lifespan ranging from a few days to about 60 years $[15,16]$. To date, over 400 NPC1 mutations are known (www.hgmd.cf.ac.uk) [17-19]. The most common mutation, I1061 T, correlates with the classical juvenile phenotype, frequently found in patients with Western European descent or in Hispanic patients who originated from the Upper Rio Grande Valley in the U.S.A. The I1061 $\mathrm{T}$ substitution results in misfolding and subsequent degradation of the mutated NPC1 protein by the proteostasis machinery [20-22].

Currently, there is no cure for NPC1 patients. The only symptomatic therapy for NPC1, approved by the European Medicines Agency, is the iminosugar miglustat ( $N$-butyldeoxynojirimycin, Zavesca ${ }^{\circledR}$ ) [23]. The ability to cross the blood-brain barrier targets miglustat for treatment of neurological symptoms in NPC1 [24,25]. Miglustat inhibits glucosylceramide synthase, a key enzyme involved in the first step of glycosphingolipid synthesis, converting ceramides (Cer) to glucocerebrosides [26]. This substrate-reduction therapy reduces the intracellular accumulation of glycosphingolipids and results in a delayed progression of neurological symptoms and a prolonged life span $[23,25,27,28]$. Another promising drug is the cyclic-oligosacccharide 2-hydroxypropyl- $\beta$-cyclodextrin $(\mathrm{HP} \beta C \mathrm{CD})$. It causes the release of cholesterol from LE/LY compartments (via a still unknown mechanism) and seems to be effective in NPC1 patients [29]. The treatment results in reduced intracellular cholesterol accumulation, and a later onset of neurological symptoms with an increased lifespan [30-32]. However, the therapy is associated with adverse side effects (e.g., hearing loss) [33]. Moreover, preliminary data of a multicenter, multinational phase $2 b / 3$ clinical efficacy trial raised doubts concerning the benefit of the therapy [34]. With the aim of improving the therapeutic approach, a combination of miglustat, $\mathrm{HP} \beta C D$ and the neurosteroid allopregnanolone (pregnan-3alpha-ol-20-one) has been applied in animal models [12,30,35-37].

The $B A L B / c N c t r-N p c 1^{m 1 N} / J$ mouse model used in this study shows a neurological phenotype with neurovisceral lipid accumulation of cholesterol and sphingolipids [38,39]. Former studies using this 
NPC1 mouse model and the combination treatment with miglustat, HP $\beta C D$ and allopregnanolone showed alleviated lipid storage in numerous organs (e.g., liver, spleen, olfactory epithelium, CNS), improved olfactory performance via increased regeneration of the olfactory epithelium, reduced cerebellar Purkinje-cell loss and decreased motor dysfunction [12,30,35-37,40,41]. Normally, the efflux of sphingolipids like sphingosine from the LE/LY is supported by the NPC1 protein [42,43]. Sphingosine is phosphorylated by sphingosine kinases (SPHK) to generate sphingosine-1-phosphate (S1P), which acts extracellularly as a bioactive signaling molecule for five G-protein coupled receptors, called sphingosine-1-phosphate receptor 1-5 (S1PR1-5) [44]. S1P/S1PR1-5 interaction triggers intracellular signaling pathways mediated by Rho-/Ras, Phospholipase C (PLC), Phosphoinositide 3-kinase (PI3 K) and protein kinase $\mathrm{B}(\mathrm{Akt})$, modulating cell survival, proliferation, differentiation, inflammation and migration of neurons and glial cells in the central nervous system [45]. Impaired sphingosine trafficking results in changed S1P level in $\mathrm{Npc1}^{-/}$mice, affecting additional pathways [40,42,43]. Speak et al. (2014) described an altered S1P level and distribution of natural killer cells in $\mathrm{Npc1}^{-/-}$mice identical to that in S1pr $5^{--}$mice [43]. Furthermore, at the molecular level there is altered S1pr expression in spleen tissue of $\mathrm{NpC1}^{-/-}$mice that can be partially prevented by treatment with miglustat, allopregnanolone and HP $\beta C D$. However, the treatment causes side effects such as a reduced number of cytotoxic $\mathrm{T}$ lymphocytes (CTLs) and raised numbers of T helper (Th) cells [40].

The current study focused on the effects of treatment on various brain regions of $\mathrm{Npcl}^{-/-}$mice by investigating molecular and cellular changes in the S1P metabolism. Additionally, we found that S1pr expression was also changed in NPC1 patient-derived samples. Consequently, we used a combination of in vivo and in vitro approaches, including NPC1 patient-derived skin material and a transgenic mouse model.

\section{Results}

\subsection{Disruption of Lipid Homeostasis in Different Brain Regions under Treatment}

Previous studies have already shown an accumulation of phospho- and sphingolipid species in different tissues of $\mathrm{Npc1}^{-/}$mice $[46,47]$. Especially the brain is strongly affected by the disturbed lipid metabolism. To identify these changes more clearly, we investigated the lipid profile of $\mathrm{Npc}^{-/}$ mice in different regions of the brain and the effect of a protective treatment with miglustat, HP $\beta C D$ and allopregnanolone via high-performance thin-layer chromatography (HPTLC, Figure 1). To better identify the lipid changes between the treatment groups, scanning profiles are also shown. Changed band intensities of the lipid classes are labeled with numbers in each brain region. TopFluor lysophosphatidic acid (LPA) was used as the internal standard, binding on the silica gel plate at retention factor (Rf) 0.13 and 0.57 (Figure S2).

\subsubsection{Parieto-Occipital Cortex (PC)}

The PC showed noticeable band differences in three lipid species (Figure 1A). Compared to sham-treated $\mathrm{Npcl}^{+/+}$mice, all of them showed weaker band intensities in sham-treated and treated $\mathrm{Npc1}^{-/}$mice. However, treated $\mathrm{Npc1}^{-/-}$mice showed stronger band intensities compared to sham-treated $\mathrm{Npcl}^{--}$mice. There were no noticeable changes in band pattern between treated and sham-treated $\mathrm{Npc}^{+/+}$mice (Figure 1A). 
A Parieto-occipital cortex (PC)

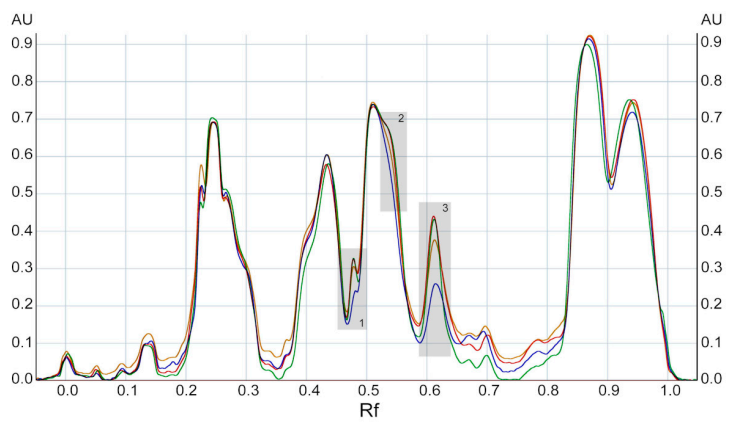

B Frontal cortex (FC)
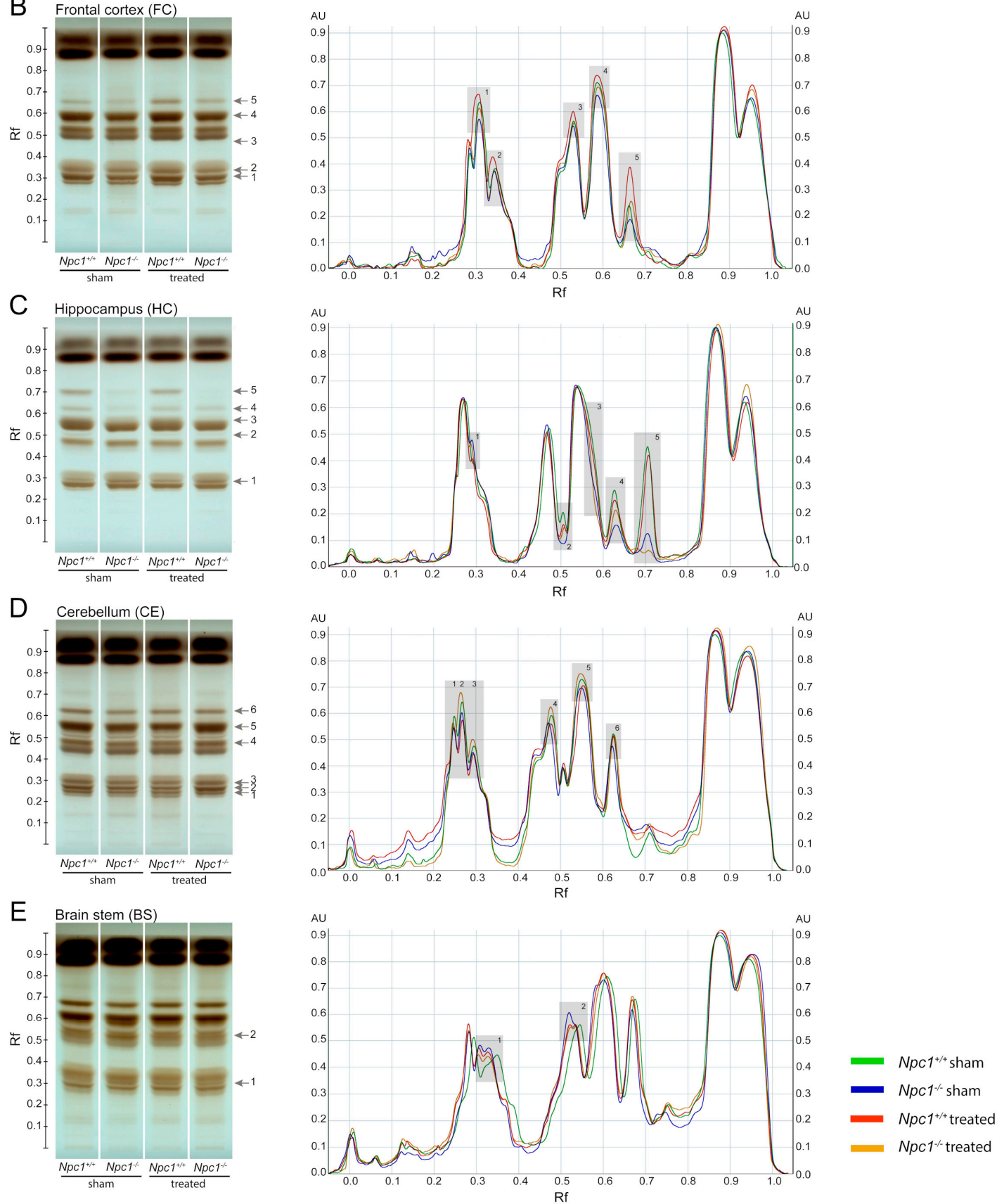

Figure 1. HPTLC (High-performance thin-layer chromatography) analysis from different brain tissues of sham-treated and treated $\mathrm{Npc}^{+/+}$and $\mathrm{Npc}^{-/-}$mice (A-E, all groups $\left.n=3\right)$. HPTLC images visualized 
the differences of phospho- and sphingolipid amounts in the four different groups. Changed lipid classes were marked with gray arrows, corresponding to the gray boxes also shown in the digital scanning profile. Band intensities of the separated lipids were calibrated in arbitrary units (AU), representing the relative absorbance. The retention factor (Rf) represents the relative distance the substance ran compared to the distance the solvent front ran. Compared to sham-treated $\mathrm{Npc}^{+/+}$mice, most of the lipids showed reduced band intensities in all brain regions of sham-treated $\mathrm{Npc}^{-/}$mice; only the brain stem showed slightly raised band intensities. The treatment of $\mathrm{Npc}^{-/}$mice results in most of the lipid classes to less pronounced changes of band intensities. However, some lipid classes also showed raised band intensities in treated $\mathrm{Npc1}^{+/+}$mice compared to sham-treated $\mathrm{Npc1}^{+/+}$mice. Scanning profiles were normalized by considering that the maximum on the normalization range (portion of the given track $\mathrm{Npc}^{+/+}$sham) represents $0.9 \mathrm{AU}$. TopFluor LPA was used as loading control (see Figure S2). LPA: lysophosphatidic acid.

\subsubsection{Frontal Cortex (FC)}

The FC showed equal changes of the band pattern in five lipid classes (Figure 1B). Compared to sham-treated $\mathrm{Npc1}^{+/+}$mice, there were weaker band intensities in sham-treated and treated $N p c 1^{-/-}$ mice and stronger intensities in treated $\mathrm{Npc1}^{+/+}$mice. However, treated $\mathrm{Npc}^{-/}$mice showed stronger band intensities than sham-treated $\mathrm{Npc1}^{-/-}$mice (Figure 1B).

\subsubsection{Hippocampus $(\mathrm{HC})$}

In the HC, five lipid species were changed (Figure 1C). Compared to sham-treated $N p c 1^{+/+}$mice, the following changes in band intensities were observed: sham-treated $N p c 1^{-/}$mice showed weaker intensities of lipid classes 2 to 5 and stronger intensity in lipid class 1 , treated $N p c 1^{-/}$mice showed stronger intensities in lipid classes 2 to 5 and weaker intensities in lipid class 1 . However, treated $\mathrm{Npc1}^{-/-}$mice showed slightly stronger intensities in lipid classes 2 to 4 and weaker intensities in lipid classes 1 and 5 compared to sham-treated $N p c 1^{-/-}$mice. There were no noticeable changes between sham-treated and treated $N p c 1^{+/+}$mice (Figure 1C).

\subsubsection{Cerebellum (CE)}

The CE, as well as the BS, showed smaller changes in band intensities than the FC, PC and the HC (Figure 1D). Compared to sham-treated $\mathrm{Npc1}^{+/+}$mice all lipid classes showed weaker band intensities in sham-treated $\mathrm{Npc1}^{-/-}$mice and treated $\mathrm{Npc1}^{+/+}$mice. All lipid classes showed stronger band intensities in treated $N p c 1^{-/}$mice compared to sham-treated $N p c 1^{-/-}$mice, whereby, lipid classes 2 to 5 showed even stronger band intensities than sham-treated $\mathrm{Npc1}^{+/+}$mice (Figure 1D).

\subsubsection{Brain Stem (BS)}

Two lipid classes were slightly changed in the BS (Figure 1E). The most distinct difference was the stronger band intensity in sham-treated $\mathrm{Npc1}^{-/-}$mice compared to sham-treated $\mathrm{Npc1^{+/+ }}$ mice. The treatment of $\mathrm{Npc1}^{-/-}$mice resulted, in both lipid classes, in similar band intensities compared to sham-treated $\mathrm{Npc1}^{+/+}$mice (Figure 1E).

Summarizing, the HPTLC analysis identified changed band intensities of various lipid classes as effects of the different treatments and depending on the brain regions.

\subsection{Characterization of Lipid Changes in Sham-Treated and Treated $\mathrm{Npc}^{-/}$Mice}

For identification of the changed lipid classes, mass spectrometry was performed (Figure 2). In this study, we focused on analyzing sphingolipids. All results are presented in ratios, compared to the sham-treated $\mathrm{Npc1}^{+/+}$mice that were set to 1 . Red boxes indicate an increase of the lipid amount, green boxes a reduction. All changes in lipid amounts are presented as tendencies. 


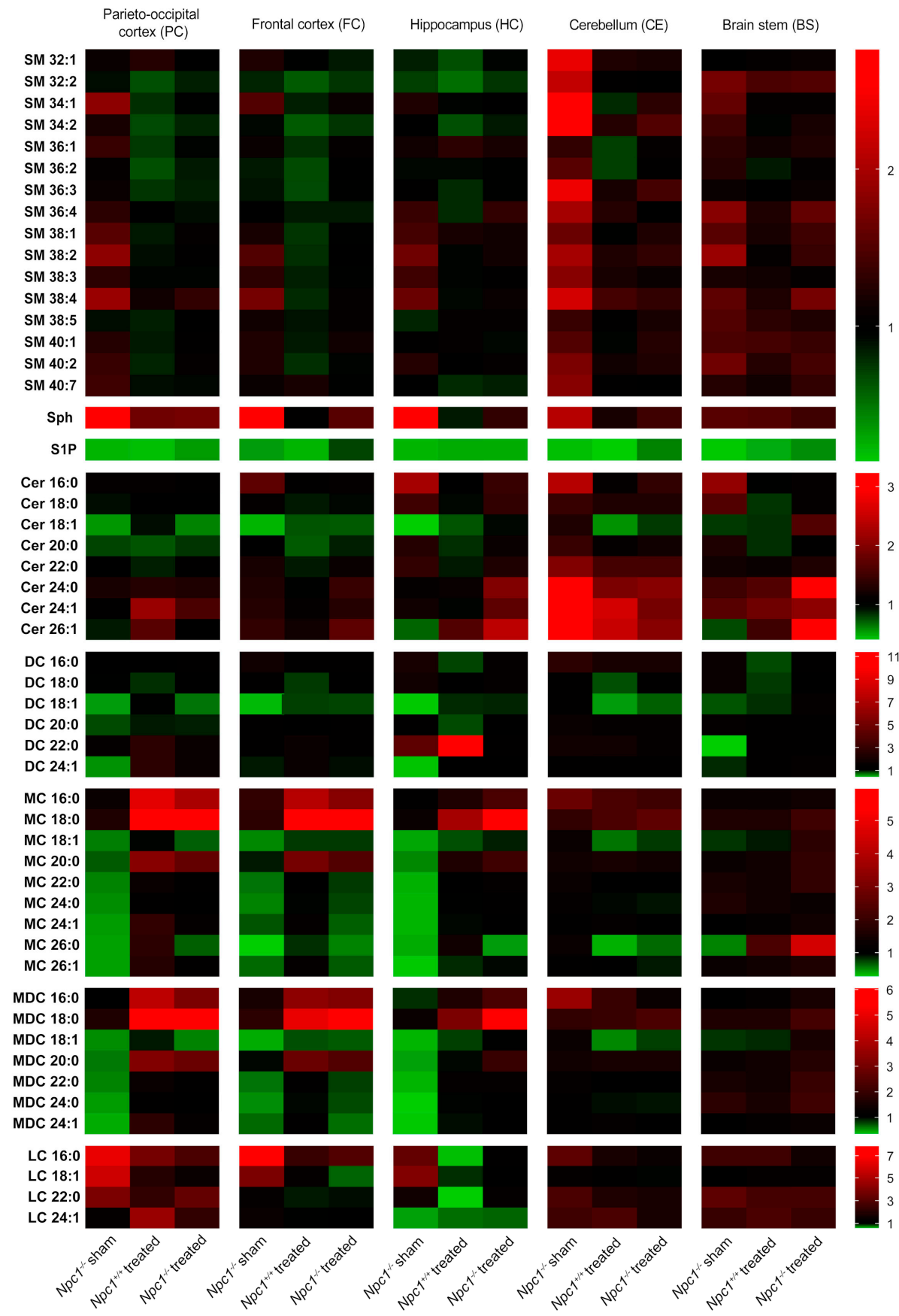

Figure 2. Heat map based on mass spectrometric analysis of sphingolipids from different brain regions of sham-treated and treated $\mathrm{Npc1}^{-/-}$mice and $\mathrm{Npc1}^{+/+}$mice (all groups $n=3$ ). Ratio of changed intensities (arbitrary units) of the appropriate lipids are shown. Green color symbolizes lower, and red color symbolizes higher intensities compared to sham-treated $\mathrm{Npc}^{+/+}$mice that were set to 1 . Notice the lower intensity of S1P in all brain regions of sham-treated $\mathrm{Npc1}^{--}$mice compared to sham-treated

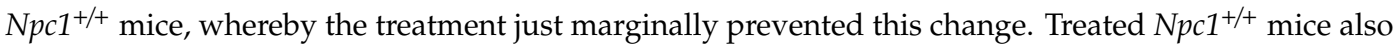
showed reduced intensities of S1P compared to the sham-treated $\mathrm{Npc1}^{+/+}$mice. In the PC, FC and HC, some lipids (MC, MDC, DC, S1P) tended to reduced intensities in sham-treated $\mathrm{Npc}^{-/}$mice compared to sham-treated $\mathrm{Npc1}^{+/+}$mice. The CE showed different changes in some lipid classes, such as 
increased intensities in SM and Cer. The treatment prevented some changes, depending on the region and the lipid class (e.g., S1P and Cer in CE-treatment effective; S1P in PC, HC and BS-treatment not effective). All data represent the mean of $n=3$ animals for all groups. Data for SM were normalized to C17-LPC. Sph was normalized to C17-Sph and S1P was normalized to C17-S1P. Data of all ceramides were normalized to C15-Cer. LPC: lysophosphatidylcholine, SM: sphingomyelin, Sph: sphingosine, S1P: sphingosine-1-phosphate, Cer: ceramide, DC: dihydroceramides, MC: monohexosyl ceramides, MDC: monohexosyl dihydroceramides, LC: lactosylceramides.

\subsubsection{Sphingomyelins (SM)}

The SM amount was only slightly changed in the respective brain regions. Sham-treated $\mathrm{Npc1}^{-/}$ mice showed a slightly increased amount in most of the SM in the PC, FC, HC and the BS, compared to sham-treated $\mathrm{Npc1}^{+/+}$mice. The treatment of the $\mathrm{Npc1}^{-/-}$mice led only to slight improvements of these changes in the PC, FC and HC, but not in the BS. The CE revealed a clear increase in most of the SM in sham-treated $\mathrm{Npc}^{-/-}$mice. This change was clearly improved by the treatment. The treatment of $\mathrm{NpC1}^{+/+}$mice led, especially in the PC, FC and HC, to slightly decreased SM amount.

\subsubsection{Sphingosine (Sph)}

Sph showed a strong increase in the PC, FC, HC and CE of sham-treated $\mathrm{Npc1}^{-/}$mice that seems to be prevented by the treatment. The BS showed almost no changes in sham-treated and treated $\mathrm{Npc}^{-/-}$mice. Treated $\mathrm{Npcl}^{+/+}$mice showed only in the PC and BS a very small increase compared to sham-treated $\mathrm{Npc1}^{+/+}$mice.

\subsubsection{Sphingosine-1-Phosphate (S1P)}

$\mathrm{S} 1 \mathrm{P}$ level showed a very distinct decrease in sham-treated $\mathrm{Npc1}^{-/}$mice in all brain regions. This effect was mostly not prevented by treatment; there was just a small increase of S1P in the PC, CE and BS of treated $\mathrm{Npc1}^{-/}$mice compared to sham-treated $\mathrm{Npc1}^{-/}$mice. The FC, however, showed a stronger protection effect by the treatment. Interestingly, the treatment of $\mathrm{Npcl}^{+/+}$mice showed a strong decrease of the S1P amount in all brain regions.

\subsubsection{Ceramides (Cer)}

Cer showed clear changes in sham-treated $\mathrm{Npc1}^{--}$mice, with a reduction of Cer 18:1 in the PC, FC and $\mathrm{HC}, \mathrm{CE}$ and BS showed almost no reduction in sham-treated $\mathrm{Npc}^{-/-}$mice, there was, however, a strong increase of Cer 24:0, Cer 24:1 and Cer 26:1 in the CE. The treatment of $\mathrm{Npc1}^{+/+}$mice showed different effects. Most of the Cer in the PC, FC, HC and BS were reduced. PC and CE also showed a small increase of some Cer (Cer 24:1 in PC; Cer 24:1 and Cer 26:1 in CE). The treatment of $\mathrm{Npc1}^{-/-}$ mice led to less pronounced reduction of Cer 18:1 in the PC, FC and HC. Likewise, the treatment led to increased Cer levels in the HC (Cer 26:1), CE (Cer 24:0, Cer 24:1, Cer 26:1) and BS (Cer 24:0, 26:1), compared to sham-treated $\mathrm{Npcl}^{+/+}$mice. Particularly the $\mathrm{CE}$ showed less pronounced changes in Cer 24:0, Cer 24:1 and Cer 26:1 by the treatment.

\subsubsection{Dihydro Ceramides (DC)}

In sham-treated $\mathrm{Npc}^{--}$mice, the DC lipid amount in the PC, FC, HC and BS tended to be reduced, especially in DC 18:1. The CE showed no changes in sham-treated $\mathrm{Npc}^{-/-}$mice. The treatment of $\mathrm{NpCl}^{+/+}$mice mostly led to a small reduction of DC in all brain regions, but exclusively DC 22:0 showed a clear increase in the HC. The treatment in $\mathrm{Npc}^{-/-}$mice resulted in small protective effects, e.g., DC 18:1 or DC 24:1 in the HC and DC 18:1 or DC 22:0 in the BS. Likewise, lipid changes tended to be prevented in DC 18:1 and DC 24:1 in the PC and DC 18:1 in the FC by the treatment. 


\subsubsection{Monohexosyl Ceramides (MC)}

The lipid amount in most of the MC was reduced in the PC, FC and HC of sham-treated $\mathrm{Npc1}^{-/}$ mice. Sham-treated $\mathrm{Npc1}^{-/-}$mice showed no clear changes in the CE. In the BS only MC 26:0 was reduced in sham-treated $\mathrm{Npc1}^{-/-}$mice. The treatment of $\mathrm{Npc1}^{+/+}$mice led to a clear increase of MC 16:0 and MC 18:0 in the PC and FC. The HC showed an increase of MC 18:0 and a reduction of MC 18:1 only in treated $\mathrm{Npc1}^{-/}$mice. The CE showed a reduced lipid amount in $\mathrm{Npc1}^{+/+}$mice of MC 18:1 and MC 26:0. The treatment of $\mathrm{Npc1}^{-/-}$mice led to a clear increase of the lipid amount, especially of MC 16:0 and MC 18:0 in the PC and FC. In the HC, the MC 18:0 showed similar changes as in the PC and FC. However, the treatment of $\mathrm{Npc}^{-/-}$mice tended to be effective in most of the MCs in the PC and the HC (except MC 26:0 in the HC).

\subsubsection{Monohexosyl Dihydroceramides (MDC)}

MDC showed the same changes as the respective MC.

\subsubsection{Lactosylceramides (LC)}

Most of the LC were increased, especially in PC and FC of sham-treated $\mathrm{Npc1}^{-/}$mice, whereas the HC showed just a small increase in the LC 16:0 and LC 18:1 amount, but a distinct decrease in LC 24:1. The treatment of $\mathrm{Npc1}^{+/+}$mice caused less smaller changes in the PC, FC, CE and BS, but distinct decreases of most LC in the HC. The increased lipid amount of sham-treated $\mathrm{Npc1}^{-/-}$mice in the PC, FC and HC tended to be prevented by treatment. CE and BS showed no clear changes of LC amounts in any brain regions.

Summarizing, the treatment prevented changes in some lipid classes. Lipid classes of some brain regions, however, showed no protective effect and in some regions side effects occurred.

For further studies, we focused on S1P, a ligand of five different S1P receptors (S1PR1-5), as the only lipid showing no protective treatment effects in $\mathrm{Npcl}^{-/-}$mice, as well as showing side effects in $\mathrm{Npc}^{+/+}$mice in all brain regions.

\subsection{Distinct Changes of S1pr3 and S1pr5 mRNA Expression in $\mathrm{Npc1}^{-/-}$Mice}

To investigate whether the disturbed lipid metabolism is associated with molecular events, various lipid receptors were analyzed. Due to the demonstrated changes of the sphingolipids in different brain regions of sham-treated and treated $\mathrm{Npc1}^{+/+}$and $\mathrm{Npc1}^{-/-}$mice, we focused on analyzing the S1prs in the same brain regions of all treatment groups using quantitative real-time PCR (qRT-PCR, Figure 3). S1pr1, S1pr3, and S1pr5 are the most strongly expressed receptors in all brain regions, whereby the S1pr3 and the S1pr5 receptors showed the strongest changes between the different groups (sham-treated $\mathrm{Npc1}^{+/+}$and $\mathrm{Npc1}^{-/-}$, treated $\mathrm{Npc1}^{+/+}$and $\mathrm{Npc1}^{-/-}$), depending on the brain region. 
A

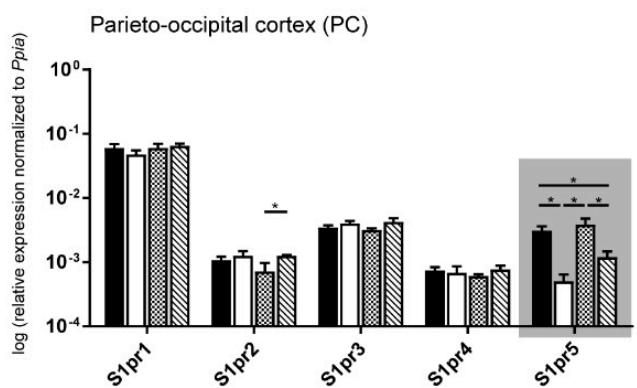

C

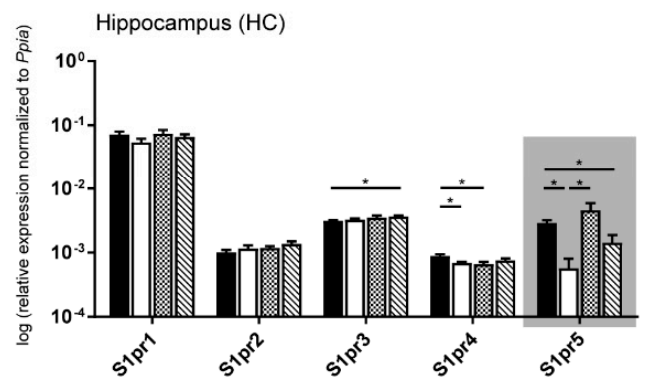

E

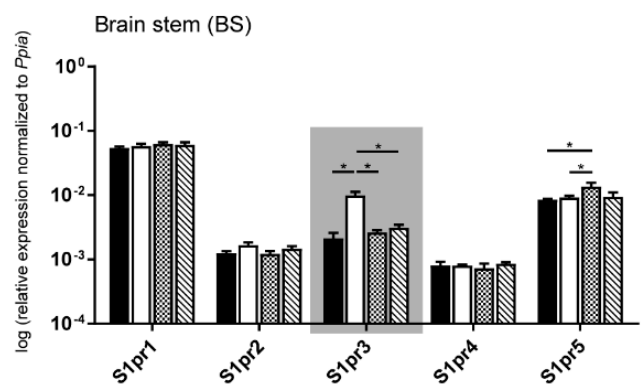

B

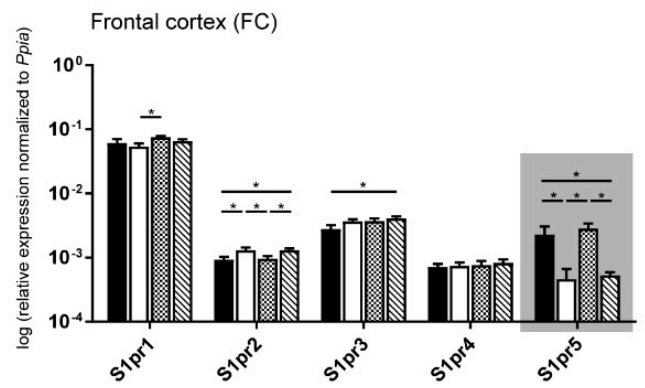

D

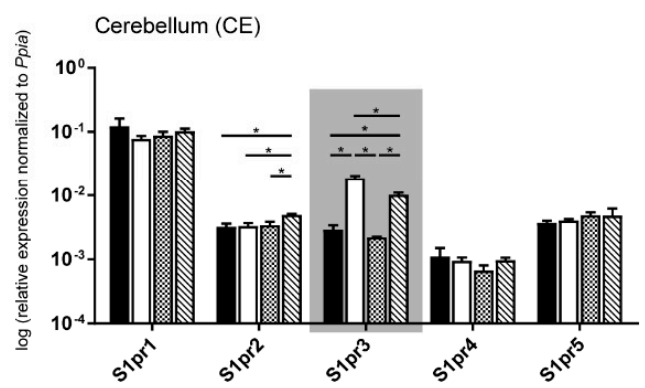

Figure 3. Quantitative RT-PCR analysis of sham-treated and treated $\mathrm{Npc1}^{+/+}$and $\mathrm{Npc}^{--}$mice revealed a distinct change in mRNA expression of S1pr3 and S1pr5 in different brain regions (marked by gray boxes). In the PC (A), the FC (B) and the HC (C), S1pr5 mRNA was significantly decreased in sham-treated $\mathrm{Npc1}^{--}$mice, whereas S1pr3 mRNA was significantly increased in the CE (D) and the BS (E). Only in the BS, the changes of S1pr3 expression are prevented by treatment. All other brain regions with changed mRNA levels of S1pr3 and S1pr5 only showed tendencies, which suggested fewer clear effects of the treatment on the transcript level. Other S1prs, however, showed significant changes in different brain regions (e.g., S1pr2 in FC and CE). Data are normalized to Ppia and are represented as mean \pm SEM with $n=3$ in all groups; $p \leq 0.05$ was considered to be significant $\left({ }^{*} p \leq 0.05\right)$. Statistical analysis was performed using the two-tailed nonparametric Mann-Whitney $U$ test. Raw data and $p$-values are listed in Table S2.

\subsubsection{Parieto-Occipital Cortex (PC)}

The PC exhibited no differences in S1pr1, S1pr3 and S1pr4 expression in all groups (Figure 3A). The S1pr 2 expression showed no changes in sham-treated $\mathrm{Npc1}^{-/-}$mice. Nevertheless, the treatment of $\mathrm{Npc}^{-/-}$resulted in a slight, but significant, increase compared to treated $\mathrm{Npc1}^{+/+}$mice. The S1pr5 expression was significantly decreased in sham-treated $\mathrm{Npc}^{-/-}$mice compared to the sham-treated and treated $\mathrm{Npc1}^{+/+}$mice. Likewise, treated $\mathrm{Npc1}^{-/}$mice exhibited a significantly decreased S1pr5 expression compared to sham-treated and treated $\mathrm{Npc}^{+/+}$mice (Figure 3A).

\subsubsection{Frontal Cortex (FC)}

The FC showed small changes in S1pr1 expression, with a discreet, but significant, increase in treated $\mathrm{Npcl}^{+/+}$mice compared to sham-treated $\mathrm{Npc1}^{--}$mice (Figure 3B). There were no other significant 
changes in S1pr1 expression. S1pr2 expression was significantly increased in sham-treated $\mathrm{Npc1}^{-1}$ mice compared to sham-treated and treated $\mathrm{Npc1}^{+/+}$mice. Equally, there was still a significant increase of treated $\mathrm{Npc1}^{--}$mice compared to sham-treated and treated $\mathrm{Npc1}^{+/+}$mice. S1pr3 showed a slight, but significant, increase in treated $\mathrm{Npc1}^{--}$mice compared to the untreated control. There were no other significant changes in S1pr3 expression. S1pr4 expression showed no changes in sham-treated and treated $\mathrm{Npc1}^{+/+}$and $\mathrm{Npc1}^{--}$mice. S1pr5, however, exhibited similar changes in all groups as in the PC. Sham-treated $\mathrm{Npc1}^{--}$showed significantly decreased S1pr5 expression compared to sham-treated and treated $\mathrm{Npc1}^{+/+}$mice. Treated $\mathrm{Npc1}^{--}$mice, however, still showed similar level to sham-treated $\mathrm{Npc1}^{--}$ mice and a significant decrease compared to sham-treated and treated $\mathrm{Npc1}^{+/+}$mice (Figure 3B).

\subsubsection{Hippocampus $(\mathrm{HC})$}

The HC presented no significant changes in S1pr1 and S1pr2 expression (Figure 3C). Nevertheless, S1pr3 did show a slightly increased expression in treated $\mathrm{Npc1}^{-/}$mice compared to sham-treated $\mathrm{Npc1}^{+/+}$mice. S1pr4 expression was slightly decreased in sham-treated $\mathrm{Npc1}^{-1-}$ mice compared to the sham-treated control. Treatment of $\mathrm{Npc}^{+/+}$mice led to a significant decrease compared to the sham-treated control. S1pr5 mRNA expression showed similar tendencies in all groups as in FC and PC. There, sham-treated $\mathrm{Npc1}^{-1-}$ mice expression was decreased compared to sham-treated and treated $\mathrm{Npc1}^{+/+}$mice. Treated $\mathrm{Npcl}^{-/}$mice showed a clear tendency to decreased expression compared to treated $\mathrm{Npc}^{+/+}$mice and a still significant decrease compared to sham-treated $\mathrm{Npc}^{+/+}$ mice (Figure 3C).

\subsubsection{Cerebellum (CE)}

In the CE there were no significant changes in S1pr1, S1pr4 and S1pr5 expression (Figure 3D). Nevertheless, S1pr2 showed a slight effect in treated $\mathrm{Npc1}^{--}$mice, with a significantly increased expression compared to the treated control, as well as to the sham-treated $\mathrm{Npc1}^{--}$and $\mathrm{Npc1}^{+/+}$mice. S1pr3 expression was significantly increased in sham-treated $\mathrm{Npc1}^{-1-}$ mice compared to sham-treated and treated $\mathrm{NpC1}^{+/+}$mice. Likewise, treated $\mathrm{Npc1}^{-/-}$mice showed a clearly significant increase compared to sham-treated and treated $\mathrm{Npc1}^{+/+}$. The treatment of $\mathrm{Npc1}^{-/}$mice also led to a significant decrease of S1pr3 expression compared to sham-treated $\mathrm{Npc1}^{--}$mice (Figure 3D).

\subsubsection{Brain stem (BS)}

The BS exhibited no changes in S1pr1, S1pr2 and S1pr4 expression in all groups (Figure 3E). S1pr3 expression showed a significant increase in sham-treated $\mathrm{Npc1}^{--}$mice compared to sham-treated and treated $\mathrm{Npc}^{+/+}$mice. Interestingly, as in the $\mathrm{CE}$, the treatment resulted in a significantly decreased expression in $\mathrm{Npcl}^{--}$mice compared to sham-treated $\mathrm{Npc1}^{-/}$mice. S1pr5 showed significantly increased expression in treated $\mathrm{Npc1}^{+/+}$mice compared to sham-treated $\mathrm{Npc1}^{+/+}$and $\mathrm{Npc1}^{-/-}$mice (Figure 3E).

Expression data $(n=3)$ are shown as mean \pm standard error of the mean (SEM). Corresponding $\mathrm{p}$ values are shown in Table S2.

Due to the most prominent changes in S1pr3 and S1pr5 mRNA expression, further studies focused on S1PR3 protein expression in the BS and CE and on S1PR5 protein expression in the PC, FC and HC.

\subsection{Changes of S1PR3/5 Protein Expression in Treated $\mathrm{Npc1}^{-1-}$ Mice}

To check the effects of changed S1pr3/5 mRNA expression on the protein level, western blot analyses were performed. To confirm the specificity of S1PR5 and S1PR3 antibody, GFP-coupled mS1pr1-5 constructs were first cloned. Digestion with specific restriction enzymes confirmed the cloned constructs shown in Figure S3A (pEGFP-mS1pr1, pEGFP-mS1pr2, pEGFP-mS1pr3, pEGFP-mS1pr4, pEGFP-mS1pr5). Subsequently, the functionality of the GFP-coupled $m S 1 p r 1-5$ constructs was shown by immunocytochemistry (Figure S3B). Purified GFP-coupled S1PR1-5 protein lysates were used to show the specificity of the S1PR3 and S1PR5 antibody. The S1PR3 and S1PR5 antibody was exclusively 
detected in the respective GFP-coupled S1PR protein lysates (Figure S3C-D). Quality and quantity of the lysates were checked using a GFP antibody, detecting respective posttranslational modified forms of all GFP-coupled S1PR1-5 proteins. Quantification of S1PR3 and S1PR5 in different brain regions of sham-treated and treated $\mathrm{Npc1}^{+/+}$and $\mathrm{Npc1}^{-/-}$mice followed.

S1PR5 protein expression analyses focused on the PC, FC and the HC, due to the changed S1pr5 mRNA expression in these same regions, as previously described (Figure $4 \mathrm{~A}-\mathrm{C}$ ). The PC and the FC showed the same tendencies as seen in S1pr5 mRNA expression. Both regions tended to slightly decreased S1PR5 protein expression in the $\mathrm{Npc}^{--}$sham, that tended to be prevented by the treatment. Nevertheless, both regions tended to an increase of S1PR5 protein expression in treated $\mathrm{Npc}^{+/+}$mice, suggesting potential treatment effects. Exclusively, treated $\mathrm{Npc1}^{+/+}$mice showed a significant increase in the FC, compared to sham-treated $\mathrm{Npc1}^{-}$mice. Compared to the respective mRNA data, the HC showed different tendencies in S1PR5 protein expression. There were no changes of S1PR5 protein expression between sham-treated $\mathrm{Npc1}^{--}$and $\mathrm{Npc1}^{+/+}$mice. The treatment of $\mathrm{Npc1}^{+/+}$mice had no effect. $\mathrm{NpC1}^{--}$mice tended to show a slightly increased protein expression upon treatment.

Due to the previously described indications in S1pr3 mRNA expression, the analyses of S1PR3 protein expression focused on the CE and BS (Figure 4D-E). The CE showed a significant increase in sham-treated $\mathrm{Npc1}^{-/-}$mice compared to sham-treated $\mathrm{Npc1}^{+/+}$mice, which could be prevented in treated $\mathrm{Npc1}^{--}$mice. Treated $\mathrm{Npc1}^{--}$mice showed significantly decreased S1PR3 protein expression compared to sham-treated $\mathrm{Npc1}^{-/}$mice. $\mathrm{Npcl}^{+/+}$mice showed no distinct changes by the treatment; nevertheless, it was significantly decreased compared to sham-treated $\mathrm{Npc1}^{--}$mice. The BS showed similar tendencies as the CE. Sham-treated $\mathrm{Npc1}^{-1}$ mice expression levels tended to be increased compared to sham-treated $\mathrm{Npcl}^{+/+}$mice. This increase tended to be prevented by treatment. Treated $\mathrm{Npc1}^{+/+}$mice showed no distinct changes, but there was a significant reduction compared to sham-treated $\mathrm{Npc1}^{-/}$mice.

In conclusion, the treatment had a prominent effect on S1PR3 protein expression, whereas S1PR5 protein expression tended to only show alterations in the brain regions PC and FC. 
A
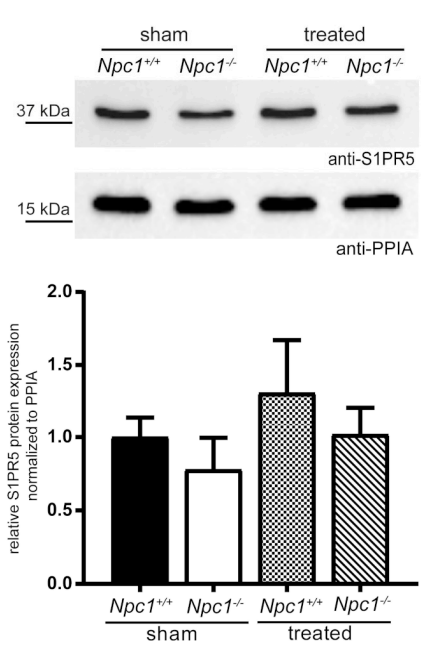

D Cerebellum (CE)
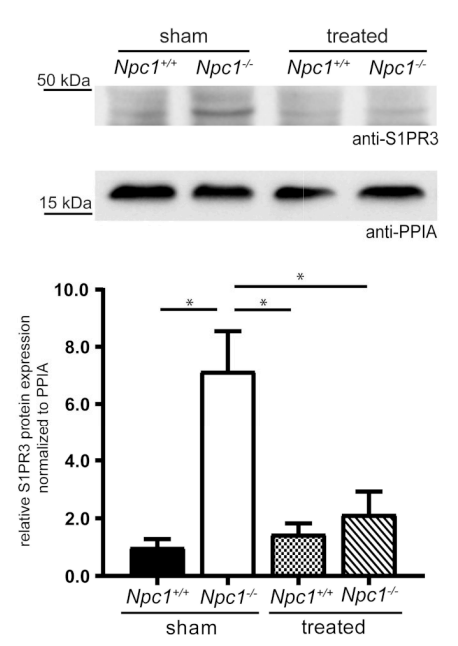

B

Frontal cortex (FC)
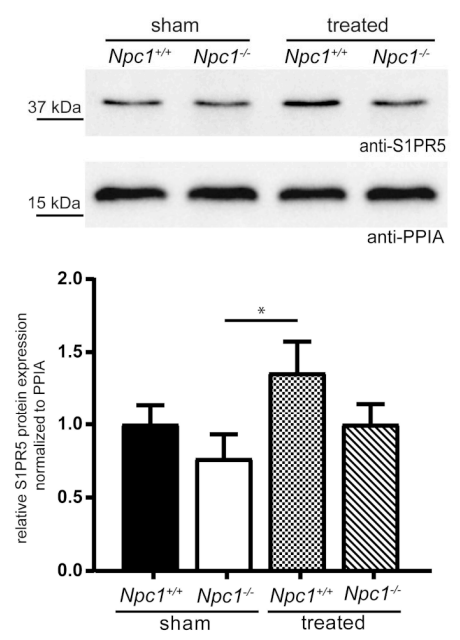

E Brain stem (BS)
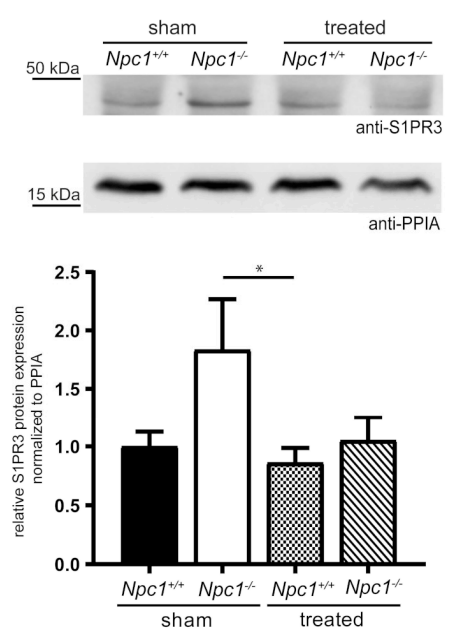

C Hippocampus (HC)
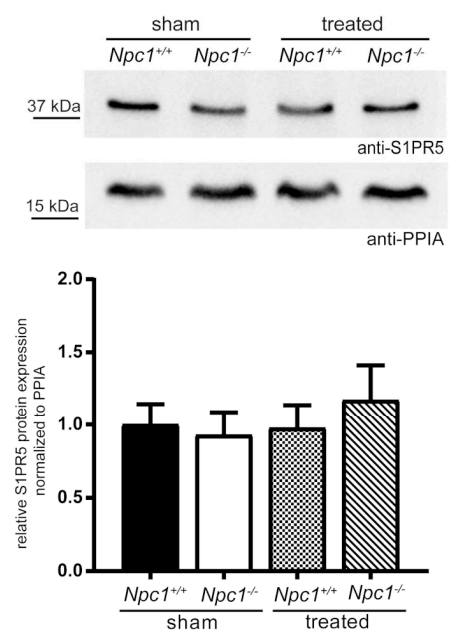

Figure 4. Semiquantitative western blot analyses of various brain regions from sham-treated and treated $\mathrm{Npc1}^{+/+}$and $\mathrm{Npc1}^{-/}$mice to detect S1PR3 and S1PR5. Membrane fractions of total protein lysates were probed with anti-S1PR3 (42 kDa) or anti-S1PR5 (42 kDa) antibody. S1PR5 protein expression was examined in PC (A), FC (B) and HC (C). PC and FC tended to reduced S1PR5 protein expression in sham-treated $\mathrm{Npc1}^{-/}$mice, compared to sham-treated $\mathrm{Npc1}^{+/+}$mice. This change tended to be prevented in treated $\mathrm{Npc}^{-/-}$mice. However, treated $\mathrm{Npc}^{+/+}$mice showed a tendency of an increase compared to sham-treated $\mathrm{Npcl}^{+/+}$mice. In contrast, in the HC, weak changes of sham-treated $\mathrm{Npc1}^{-/}$mice could be observed. Nevertheless, treated $\mathrm{Npc1}^{--}$mice showed increased S1PR5 protein expression compared to the respective sham-treated mice. The S1PR3 protein expression was examined in the CE (D) and BS (E). The CE showed a significant increase in sham-treated $\mathrm{NpC1}^{--}$mice, compared to sham-treated $\mathrm{Npc1}^{+/+}$mice, which was prevented by the treatment, showing a significant reduction in treated $\mathrm{Npc1}^{-/}$ mice compared to sham-treated $\mathrm{Npc1}^{--}$mice. The BS showed the same changes as the CE. However, there was a small tendency of increased S1PR3 expression in sham-treated $\mathrm{Npc1}^{--}$mice compared to sham-treated $\mathrm{NpC1}^{+/+}$mice, that tended to be prevented by treatment, showing a decrease of treated $\mathrm{Npc1}^{--}$mice compared to sham-treated $\mathrm{Npc1}^{--}$mice. Protein levels were quantified and normalized according to the levels of PPIA (18 $\mathrm{kDa}$ ). Experiments were repeated with $n=4$ to 5 biologic controls and $N=3$ technical controls. Data represent the ratio of the mean \pm SEM (sham-treated $N p c 1^{+/+}$set to 1$) . p \leq 0.05$ was considered to be significant $\left({ }^{*} p \leq 0.05\right)$. Statistical analysis was performed using the two-tailed nonparametric Mann-Whitney $U$ test. 


\subsection{Cell-Type-Specific mRNA Expression of S1PRs}

To analyze how the changed S1pr expression in $\mathrm{Npc1}^{--}$mice affected cellular events, initially cell-type-specific localization of S1pr1-5 mRNA in mouse primary cells were investigated via qRT-PCR analysis (Figure S4). S1pr1 and S1pr2 showed high expression in astrocytes, neurons, microglia and oligodendrocytes compared to all other S1prs. S1pr3 was the highest expressed receptor in astrocytes; it was, however, also expressed in neurons and oligodendrocytes. S1pr3 had a very low expression in microglia. S1pr4 was expressed in microglia, neurons and oligodendrocytes, but showed a very low expression in astrocytes. The S1pr5 expression in astrocytes, microglia and neurons was very low or below the detection level. Interestingly, a strong S1pr5 expression in oligodendrocytes was shown.

\subsection{Treatment Did Not Prevent Reduction of the Diameter of the Corpus Callosum}

This fact-and the very distinct change in S1pr5 expression in sham-treated and treated $\mathrm{Npc1}^{-1}$ mice compared to sham-treated $\mathrm{Npc1}^{+/+}$mice-suggested performing morphometric analyses in white matter areas, such as corpus callosum (Figure 5A). Measuring the diameter confirmed the - already shown - reduction of the corpus callosum in $\mathrm{Npc1}^{-1-}$ mice [48,49], but the treatment of $\mathrm{Npc1}^{--}$mice did not prevent the reduction of the corpus callosum. It was still significantly reduced compared to sham-treated $\mathrm{Npc}^{+/+}$mice. Additionally, transmission electron microscopy of sham-treated $\mathrm{Npc1}^{-/-}$mice showed impaired nerve fibers, that were loaded with autophagosomes and defects in myelination in the corpus callosum, as previously shown by Bräuer et al. [34]. To examine whether the reduced corpus callosum and myelination defects are correlated, immunohistochemical analyses with $2^{\prime}, 3^{\prime}$-cyclic-nucleotide 3'-phosphodiesterase (CNPase), a marker for myelinated fibers and oligodendrocytes, were performed (Figure 5B-C). Interestingly, this study showed the same tendencies in sham-treated and treated $\mathrm{Npc1}^{--}$ and $\mathrm{NpC1}^{+/+}$mice (no statistical analyses were performed due to small number of mice), strengthening the assumption that changes in S1pr5 mRNA expression in oligodendrocytes and the decrease of corpus callosum diameter are correlated.

A

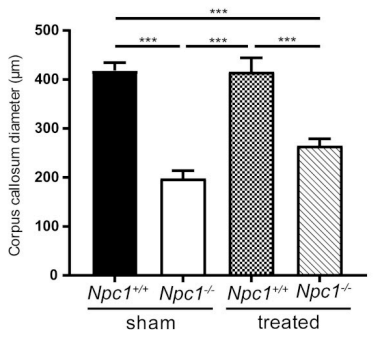

B

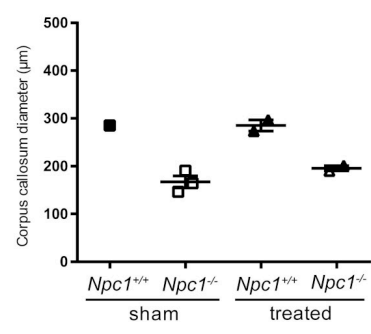

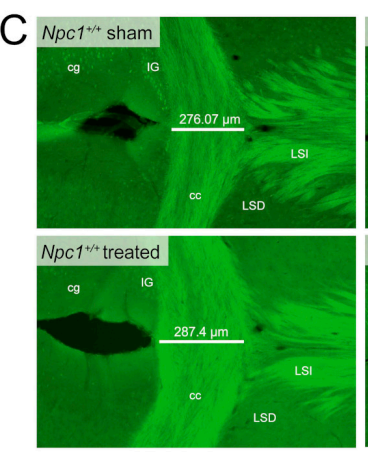

Figure 5. Morphometric analysis of the corpus callosum diameter from Nissl-stained brain sections of

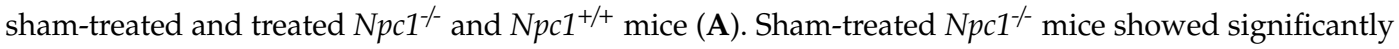
reduced corpus callosum diameter compared to the respective $\mathrm{Npc1}^{+/+}$mice. Interestingly, the treatment of $\mathrm{Npc1}^{--}$mice tended to show a slight protection effect on the thickness of the corpus callosum, that is, however, not significant. Statistical analysis was performed using one-way analysis of variance (ANOVA) followed by Bonferroni correction of multiple comparisons ( $N p c 1^{+/+}$sham: $n=10$; $\mathrm{Npc}^{-/}$ sham, $n=9 ; N p c 1^{+/+}$treated: $n=6 ; N p c 1^{--}$treated: $n=6$ ). Data are given as the mean $\pm \mathrm{SEM}$ and considered significant if $\left.p \leq 0.001{ }^{* * *} p \leq 0.001\right)$. Immunohistochemical analysis of the corpus callosum diameter $(\mathbf{B}-\mathbf{C})$ were performed to investigate the extent to which the reduction of the corpus callosum diameter was correlated with impaired myelination of nerve fibers (see Bräuer et al.) [34] and thus 
oligodendrocytes. CNPase, a marker for oligodendrocytes and myelinated fibers, were used for immunostaining. Interestingly, the measurement the corpus callosum diameter (B) sowed, in accordance with the appropriate immunohistochemical images $(\mathbf{C})$ the same tendencies as the previously described morphometric analysis of the corpus callosum. The corpus callosum diameter was measured on each serial section per mouse brain (29 sections \pm 3 of each group). Data are given as mean $\pm \mathrm{SEM}$. No statistical test was performed due to the small number of mice involved ( $N p c 1^{+/+}$sham: $n=1 ; \mathrm{Npc1}^{-/}$ sham: $n=3 ; N p c 1^{+/+}$treated: $n=2 ; N p c 1^{--}$treated: $\left.n=2\right)$. Scale bar in the right lower picture, in the right lower corner: $200 \mu \mathrm{m}$. cg: cingulate cortex; cc: corpus callosum; IG: indusium griseum; LSD: dorsal lateral septum; LSI: intermediate lateral septum.

\subsection{Is the S1pr1-5 Expression Affected in Human NPC1 Mutant Fibroblasts?}

For the first time, S1pr1-5 expression analyses in human NPC1-deficient fibroblasts were performed to evaluate whether the alterations in $\mathrm{Npc1}^{--}$mice are also detectable in human patient-derived cell lines. Patient-derived NPC1-deficient fibroblasts of two affected siblings (sibling 1, sibling 2, Figure 6A), both carrying the same NPC1 mutation (c.3182 T>C), were used to analyze the S1pr1-5 expression at different passaging numbers in cell culture procedures (Figure 6B). Both patients were treated with miglustat for about twelve years before skin biopsy and culturing the fibroblasts. In the expectation that miglustat would be washed out through repeating splitting procedures, fibroblasts were cultivated for 15 splitting procedures (p), analyzing the S1pr expression at p1, p5, p10 and p15. First, filipin staining (Figure S5) showed an accumulation of cholesterol in NPC1-deficient fibroblasts ( $\mathrm{p} 5$ of sibling 1 and 2) and fibroblasts of an apparently healthy individual, obtained from Coriell Institute for Medical Research (control: GM08398). Fibroblasts of sibling 1 and sibling 2 showed a distinct clustered accumulation of cholesterol compared to the homogeneously distributed cholesterol of the control. To examine the expression of S1pr1-5 mRNA over 15 splitting procedures, qRT-PCR analyses revealed different tendencies of each S1pr mRNA in both patients. Expression data were not compared to fibroblasts of an apparently healthy family member because these were not available. Fibroblasts of another apparently healthy individual were not used, because no information about treatment and other diseases was available. Sibling 1 showed slight tendencies of increased S1pr1 mRNA at p5, compared to $\mathrm{p} 1$, but during the processes it tended to be decreased. S1pr2 and S1pr4 also tended to decreased mRNA expression during the process of additive splitting procedures. However, S1pr3 and S1pr5 mRNA tended to be increased during the splitting processes. Sibling 2, who is less affected (weaker symptoms) than sibling 1, showed similar effects, but only for some receptors (S1pr1, S1pr2). S1pr1 mRNA tended to an increase in $\mathrm{p} 5$, compared to $\mathrm{p} 1$, but tended to be decreased during the following splitting procedures. S1pr 2 mRNA tended to be reduced during the splitting processes. S1pr3 tended to be decreased at $\mathrm{p} 5$, compared to $\mathrm{p} 1$ and tended to be increased during subsequent splitting procedures. S1pr4 and S1pr5 showed different tendencies in sibling 2 compared to sibling 1. Initially, S1pr4 mRNA tended to be reduced until p10, but then to be increased at p15 (compared to p10). S1pr5 mRNA tended to be strongly decreased at p5, p10 and p15 (compared to p1). Interestingly, the S1pr5 mRNA expression level of sibling 2, the less affected patient, is clearly higher than in sibling 1. In summary, all S1prs are expressed in human fibroblast and showed variations, depending on the severity of the disease. 


\begin{tabular}{|c|c|c|}
\hline & Sibling 1 & Sibling 2 \\
\hline Mutation & c.3182T>C $[p . \mid 1061 T]$ & c.3182T>C $[p . \mid 1061 T]$ \\
\hline Genotype & homozygous & homozygous \\
\hline Age at diagnosis & 12 years, 8 months & 12 years \\
\hline Current age & 26 years & 24 years, 10 months \\
\hline Start of the treatment (miglustat) & $04 / 16 / 2007$ & $06 / 18 / 2007$ \\
\hline Dosage of miglustat & $3 \times 200 \mathrm{mg}$ & $3 \times 200 \mathrm{mg}$ \\
\hline Symptoms at diagnosis & $\begin{array}{l}\text { - vertical gaze palsy } \\
\text { - movement disorder (hypotonic-atactic) } \\
\text { - splenomegaly } \\
\text { - cataplexy } \\
\text { - dysarthria }\end{array}$ & $\begin{array}{l}\text { - vertical gaze palsy } \\
\text { - movement disorder (hypotonic-atactic) } \\
\text { - splenomegaly }\end{array}$ \\
\hline Current symptoms/ health status & $\begin{array}{l}\text { - progressive ataxia with pyramidal and } \\
\text { extrapyramidal signs } \\
\text { - patient can still walk independently } \\
\text { - minor impairment of intelligence }\end{array}$ & $\begin{array}{l}\text { - dysarthria } \\
\text { - progressive ataxia with pyramidal and } \\
\text { extrapyramidal signs } \\
\text { - minor impairment of intelligence } \\
\text { - altogether less affected than sibling } 1\end{array}$ \\
\hline Other disorders & obesity & obesity \\
\hline
\end{tabular}

B Relative expression of S1pr1-5 mRNA in NPC1-deficient fibroblasts derived from patients
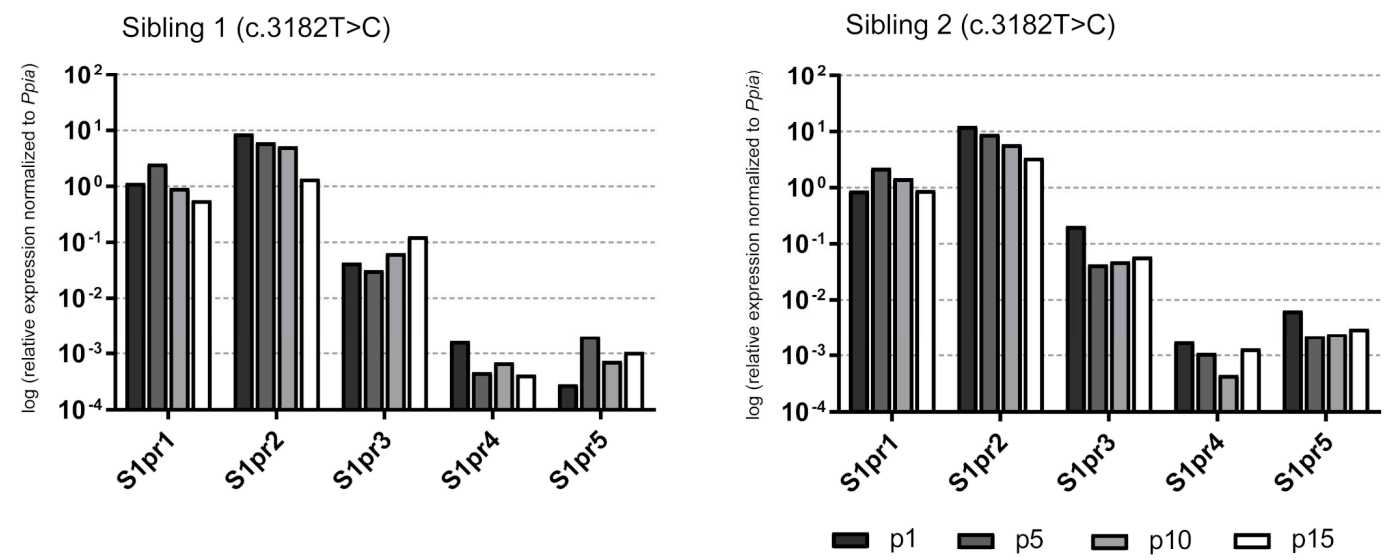

Figure 6. Characterization of the NPC1 disease of two siblings carrying the homozygous mutation c.3182 T>C (A). Both patients show neurological manifestations, such as ataxia, as well as visceral symptoms (splenomegaly). Fibroblasts of both siblings were used for further experiments: qRT-PCR was performed (B), suggesting that multiple washing steps could change the miglustat concentration in fibroblasts. S1pr1-5 mRNA expression in NPC1-deficient fibroblasts were analyzed over 15 splitting procedures (p). Comparing the expression at p15 to that at $\mathrm{p} 1$, sibling 1 tended to reduce S1pr1, S1pr2 and S1pr4 mRNA and increased S1pr3 and S1pr5 mRNA level. Sibling 2 reveals similar changes in S1pr1 and S1pr2 expression. Comparing the expression of $\mathrm{p} 15$ to $\mathrm{p} 1$, however, sibling 2 also showed decreased expression of S1pr3, S1pr4 and S1pr5. Interestingly, S1pr5 expression level was clearly decreased in sibling 1 , the symptomatically more affected patient, compared to sibling 2 . $N=1$ technical control, normalized to Ppia. p1, p5, p10, p15 = passaging number of fibroblasts.

\subsection{Altered S1pr5 Expression in Human Cells Derived from Induced Pluripotent Stem Cells (iPSCs)}

In another experiment, we used patient-specific fibroblasts (control: GM05659; Npc1 homozygous mutated: GM18453, c.3182 T>C), iPSC-derived neural progenitor cells (NPCs) and neuronal differentiated cells (NDCs) (Figure S6A-C) to analyze S1pr1-5 mRNA expression. Unfortunately, there is no additional information about the patient carrying the NPC1 mutation. Interestingly, the fibroblasts showed a significant reduction of S1pr1 and S1pr2 mRNA and a significant increase in S1pr5 mRNA. 
S1pr3 mRNA was not changed and S1pr4 mRNA tended to be reduced. iPSC-derived NPCs showed the opposite of the fibroblasts, with a significant reduction of S1pr5 mRNA. S1pr1, S1pr2, S1pr3 and S1pr4 showed now significant changes. iPSC-derived NDCs showed similar changes to NPCs with a significant reduction of S1pr5 mRNA. Additionally, NDCs showed an increase of S1pr1 mRNA. S1pr2, S1pr3, S1pr4 now showed significant changes. Summarizing, S1pr5 mRNA showed the most pronounced changes in the different cell types. The fibroblasts showed a strong increase, whereas the NPCs and NDCs showed contrary changes, with a strong reduction in S1pr5 mRNA. S1pr5 presents the most interesting changes in human NPC1 mutant fibroblasts and iPSC-derived cells.

\section{Discussion}

In the current study, using quantitative molecular and cellular techniques in the brains of $\mathrm{Npc1}^{-1}$ mice, we showed for the first time that S1P metabolism changes after treatment with miglustat, allopregnanolone and $\mathrm{HP} \beta \mathrm{CD}$. The structural and functional heterogeneity of the brain motivated us to investigate treatment effects in different brain regions (parieto-occipital cortex, frontal cortex, hippocampus, cerebellum and brain stem). Based on previous studies of treatment effects in the spleen [40], liver [36] and the olfactory system [35,41], our data partly confirmed the protective effects in the brain, but not to the same extent. Interestingly, our analysis at the molecular level demonstrated side effects in treated $\mathrm{Npcl}^{+/+}$mice that were also shown in previous studies at the cellular level of the spleen, showing a changed Th cell/CTLs ratio [40].

\subsection{Weak Improvement of the S1P Metabolism in Treated $\mathrm{Npc1}^{-1-}$ Mice}

Previous studies from Neßlauer et al. [40], Ebner et al. [36] and Meyer et al. [35,41] investigated the effects of the treatment in spleen, liver and the olfactory system, resulting mostly in cellular and molecular improvements of the NPC1 characteristics. However, our investigations of the treatment effects in the brain did not confirm protection effects of the same magnitude. Depending on the brain region, some lipid classes were differently protected by treatment. However, S1P was the only lipid that presented reduced lipid levels in all brain regions of sham-treated and treated $\mathrm{Npc}^{-\digamma}$ mice. Expression analysis of the associated S1prs revealed similar effects in most brain regions. S1pr3/S1PR3 and S1pr5/S1PR5 underwent the most prominent changes in S1pr/S1PR expression. S1pr3/S1PR3 was significantly increased in $\mathrm{CE}$ of sham-treated $\mathrm{Npc1}^{-\gamma}$ mice. It is involved in neuroinflammatory gene expression in astrocytes, mediated by RhoA signaling [50]. Previous studies showed cerebellar astrogliosis in $\mathrm{Npc1}^{--}$mice [51,52]. These findings led to the assumption that an S1pr3/S1PR3 increase may play a role in astrocyte activation in $\mathrm{Npc1}^{-/}$mice. Interestingly, the treatment showed a significant effect at the mRNA expression level—and at the protein level—it also seemed to show a protective effect, suggesting that the treatment may act on different regulation levels. The opposite effect was revealed by S1pr5 expression. It was significantly decreased in the PC, FC and HC, responding under treatment only with small changes. S1pr5/S1PR5 is mainly expressed in oligodendrocytes, occurring extensively in the white matter. It is associated with oligodendrocyte proliferation, survival and inhibition of migration of oligodendrocyte precursor cells [53,54]. More detailed studies need to be conducted regarding the treatment effects on S1pr/S1PR expression and the entire S1P homeostasis of different brain regions.

\subsection{Weak Treatment Effects at the Cellular Level in the White Matter}

Metabolites of the sphingolipid metabolism, like MC and SM, are major components in the white matter, that are interesting especially regarding neurodegenerative diseases like NPC1 or multiple sclerosis [46,55-58]. Our lipid analysis in $\mathrm{Npc1}^{--}$mice confirmed changes in MC, SM and SM metabolites, whereby SM and Sph revealed increased lipid levels and S1P decreased levels in the different brain tissues. Previous studies of human NPC1-deficient fibroblasts [59] and human plasma samples [46] of NPC1 patients also showed reduced S1P levels. However, some previous studies also reported 
increased S1P levels in spleen [40], lymph nodes [43] and total brain of $\mathrm{Npc1}^{-1-}$ mice [42,46], that are not consistent with our results. Possible reasons for this need to be investigated.

S1P acts as a signaling molecule for five S1PRs that are abundant in the brain [60]. Our expression analyses in all brain regions of $\mathrm{Npc1}^{--}$mice showed a distinct change of S1pr3 and S1pr5 expression, depending on the brain regions (an S1pr3 increase in CE and BS and a S1pr5 decrease in PC, FC and $\mathrm{HC}$ ). Further analysis identified expression of S1pr3 in astrocytes, oligodendrocytes and neurons, whereby S1pr5 was mainly expressed in oligodendrocytes. Increased S1pr3 mRNA expression was also demonstrated in brain tissue in experimental autoimmune encephalomyelitis (EAE), a model of multiple sclerosis [61,62] and in a mouse model of Sandhoff disease, another lipid storage disease that showed a milder course with reduced proliferation of glial cells and less astrogliosis in S1 pr $3^{--}$ mice suffering from Sandhoff disease. This suggested that S1pr3 may contribute to neurodegenerative diseases [63,64]. S1pr5 plays a role in oligodendrocyte differentiation. Jaillard et al. [53] showed that S1pr5 mediates two functional pathways, depending on the developmental stage of the oligodendroglial cells. On one hand, it mediates process retraction in immature oligodendrocytes and on the other hand it promotes survival in mature oligodendrocytes, but not in pre-oligodendrocytes.

Based on the myelination defects in $\mathrm{Npc}^{-/}$mice $[34,48,49]$, we suggested that changes in oligodendrocyte-expressed S1prs may be correlated with white matter/myelinization defects. The measurement of the corpus callosum diameter confirmed previous data of reduced corpus callosum diameter in $\mathrm{Npcl}^{-/}$mice. Interestingly, we found that the treatment had no effects in $\mathrm{NpC1}^{-}$mice. Furthermore, immunohistochemical analysis using a marker for myelinated fibers revealed the same tendencies in sham-treated and treated $\mathrm{NpC1}^{-1-}$ mice when comparing morphometric measurements of the corpus callosum. These results suggested a correlation between changed S1pr expression and myelinization/white matter defects and showed that the treatment has no protective effects on white matter.

\subsection{Side Effects of the Treatment in $\mathrm{Npc1}^{+/+}$Mice}

To date, NPC1 disease is not curable. Miglustat, the only approved drug in Europe, is only used for symptomatic treatment, especially reducing glycosphingolipid accumulation in the LE/LY system [28]. Likewise, $\mathrm{HP} \beta \mathrm{CD}$, mediating the excretion of cholesterol in $\mathrm{Npc}^{--}$mice, represents another promising drug [29]. Clinical trials by Matsuo et al. [31] and Ory et al. [65] in NPC1 patients seemed to be effective, suggesting $\mathrm{HP} \beta C D$ as a potential therapy for NPC1 patients. However, a current multinational phase $2 b / 3$ clinical study has raised doubts concerning the positive effects of $H P \beta C D$ [34]. In addition, $\mathrm{HP} \beta C D$, as well as miglustat, have side effects, such as tremor, weight loss or gastrointestinal problems induced by miglustat [66] and hair loss induced by $\operatorname{HP} \beta C D$ [33]. As shown in previous studies, there was side effects of the treatment at the cellular level in the spleen [40], showing a decreased number of CTLs and an increased number of Th cells. The treatment used in our study was also associated with side effects on S1P metabolism. Our present study, analyzing treatment effects in the brain, presented side effects on the S1P level in all brain regions with a strongly decreased S1P lipid amount. Beside S1P, other lipids showed changes, such as a strong increase of MC 18:0 and MDC 18:0 in the PC and FC and Cer 24:1 and Cer 26:1 in the CE or a decrease of LC 16:0 and LC 22:0 in the HC. Whether these effects are caused by miglustat or HP $\beta C D$ needs to be investigated. This demonstrated the need to examine further promising treatments. The group of Sarah Spiegel [67] demonstrated that S1P functions as an endogenous inhibitor of class1/2 histone deacetylases (HDAC). Fingolimod (FTY720), a drug approved for treatment of multiple sclerosis, is a sphingosine analog and able to enter the nucleus. The active phosphorylated form (FTY720-P) accumulates in the CNS and also functions as an HDAC inhibitor to regulate gene expression [68]. Current studies showed increased NPC1 and NPC2 expression in fibroblasts of patients with NPC1 after FTY720 treatment, combined with decreased cholesterol and sphingolipid accumulation [69]. The accumulation in the CNS and the sole regulation of genes restricted to sphingolipid metabolism identified FTY720 as a promising treatment for NPC1 patients with neurological symptoms. 


\section{Materials and Methods}

\subsection{Animals}

Heterozygous breeding pairs of NPC1 mice (BALB/cNctr-Npc1 $\left.1^{m 1} \mathrm{~N} / \mathrm{J}\right)$ were obtained from Jackson Laboratories (Bar Harbor, ME, USA) for generating homozygous $N p c 1^{-/}$mutant mice and $N p c 1^{+/+}$ control wild-type mice. Transgenic mice at postnatal day 65 (P65) were used for RNA, protein and lipid analyses, as well as mass spectrometric analysis and measurement of corpus callosum diameter. For preparation of oligodendrocytes, postnatal BALB/c mice were obtained from the central animal facility of the University Medical Center Rostock. Approval of the experiments was obtained from the "Landesamt für Landwirtschaft, Lebensmittelsicherheit und Fischerei Mecklenburg-Vorpommern" (May 2016: LALLF: 7221.3-1.1-011/16, June 2012: 7221.3-1.1-030/12).

For preparation of astrocytes, microglia and neurons, timed-pregnant and postnatal wild type C57BL/6 mice were obtained from the central animal facility (FEM) of the Charité-Universitätsmedizin Berlin. Approval of the experiments was obtained from the „Landesamt für Gesundheit und Soziales Berlin“(April 2011: LAGeSO: T0108/11).

Mice were maintained under standard laboratory conditions with $12 \mathrm{~h}$ day/night cycle, a temperature of $22{ }^{\circ} \mathrm{C}$, a relative humidity of $60 \%$ and free access to food and water. This study was carried out in accordance with German and European guidelines (2010/63/EU) for the use of laboratory animals.

\subsection{Genotyping}

Genotyping of NPC1 mice until P7 was performed by PCR analysis. Direct PCR tail with proteinase $\mathrm{K}$ were used for homogenization of $1-2 \mathrm{~mm}$ cut tail, incubating at $55{ }^{\circ} \mathrm{C}$ for $16 \mathrm{~h}$ overnight with agitation (750 rpm, ThermoMixer ${ }^{\circledR}$ C, Eppendorf, Hamburg, Germany). Lysates were centrifuged at $2400 \times g$ for $30 \mathrm{~s}$. PCR analysis was performed using $2 \mu \mathrm{L}$ lysate and two different primer pairs under equal cycling conditions. To detect the $475 \mathrm{bp}$ fragment of the mutant allele, the following primer pair was used: $5^{\prime}$-ggtgctggacagccaagta-3' and 5'-tgagcccaagcataactt-3'. To detect the $173 \mathrm{bp}$ fragment of the wildtype allele the primers were: $5^{\prime}$-tctcacagccacaagcttcc- $3^{\prime}$ and $5^{\prime}$-ctgtagctcatctgccatcg- $3^{\prime}$.

\subsection{Pharmacologic Treatment}

$\mathrm{Npc1}^{+/+}$and $\mathrm{Npc1}^{-/}$mice were treated with a combination of allopregnanolone (Sigma-Aldrich, St. Louis, MO, USA), HP $\beta C D$ (Sigma-Aldrich) and miglustat (Actelion Pharmaceuticals, Allschwil, Switzerland), further referred to as "treated". Control $\mathrm{Npc1}^{+/+}$and $\mathrm{Npc1}^{-/}$mice received Ringer's solution (B. Braun Melsungen AG, Melsungen, Germany) or 0.9\% normal saline solution (Carl Roth $\mathrm{GmbH}$, Karlsruhe, Germany) and are further referred to as "sham-treated". The treatment scheme (Figure S1) started at P7 with a weekly intraperitoneal injection of allopregnanolone $(25 \mathrm{mg} / \mathrm{kg})$ dissolved in HP $\beta C D$ (4000 mg/kg, dissolved in Ringer's solution) as previously described $[30,35,36,40]$. Additionally, mice received a daily intraperitoneal injection of miglustat $(300 \mathrm{mg} / \mathrm{kg}$, dissolved in $0.9 \%$ normal saline solution) starting at P10 until P22. Afterwards, daily uptake was ensured by mixing miglustat powder $(1200 \mathrm{mg} / \mathrm{kg})$ with standard chow until P65. Sham-treated mice followed the same treatment scheme, receiving Ringer's solution (B. Braun Melsungen AG) or 0.9\% normal saline solution (Carl Roth $\mathrm{GmbH}$ ).

\subsection{Tissue Sampling}

Sham-treated and treated $\mathrm{Npc1}^{+/+}$and $\mathrm{Npc1}^{-/}$mice were deeply anesthetized with pentobarbital (90 mg/kg body weight, AbbVie, Berlin, Germany) and decapitated at P65. Subsequently, different brain regions were dissected: cortex, hippocampus (HC), cerebellum (CE) and brain stem (BS). The cortex was divided into frontal and parieto-occipital parts, referred to as frontal cortex (FC) and parieto-occipital cortex (PC). All brain regions were snap-frozen in liquid nitrogen and stored at $-80^{\circ} \mathrm{C}$. The non-perfused tissue was used for HPTLC, mass spectrometry, qRT-PCR and western blot analyses. 


\subsection{Lipid Extraction}

Lipids of different brain regions of sham-treated and treated $\mathrm{Npc1}^{+/+}$and $\mathrm{Npc1}^{--}$mice, stored at $-80^{\circ} \mathrm{C}$, were extracted according to Bligh and Dyer (1959) [70], with slight modifications. The tissues were weighed and subsequently homogenized with the PT 3100D homogenizer (Kinematica AG, Luzern, Switzerland) in a mixture of chloroform, methanol and 37\% hydrochloric acid (ratio 2:4: 0,1; all from Merck KGaA, Darmstadt, Germany) supplemented with $140 \mu \mathrm{L}$ of $1 \%$ butylated hydroxytoluene (Merck KGaA), to prevent lipid oxidation. Then, $1.25 \mathrm{~mL}$ chloroform, $1.25 \mathrm{~mL}$ HPTLC water (Carl Roth $\mathrm{GmbH}$ ) and $5 \mu \mathrm{L} / 50 \mathrm{mg}$ brain tissue of the fluorescent standard TopFluor LPA (810280P, Sigma-Aldrich) were added to the tissue and incubated at room temperature (RT) for $30 \mathrm{~min}$. TopFluor LPA was used as internal standard, ensuring the analysis of the same lipid amount in all compared samples (Figure S2) [71]. Samples were centrifuged at $1260 \times \mathrm{g}$ for $10 \mathrm{~min}$, resulting in a triphasic separation. The bottom phase, containing a mixture of chloroform and lipids, was transferred into a brown glass vial and evaporated overnight in a nitrogen chamber at $50{ }^{\circ} \mathrm{C}$. Subsequently, the vials were stored at $-20{ }^{\circ} \mathrm{C}$.

\subsection{Separation and Analysis of Lipid Classes by High-Performance Thin-Layer Chromatography (HPTLC)}

Previously extracted lipid samples were dissolved in chloroform at a concentration according to their weight and tissue type. Additionally, chromatographic standards (dissolved in chloroform) were used, assigning changes in the lipid profile to certain lipid classes. HPTLC was used to separate and visualize lipids using silica gel as stationary phase. Lipid samples and chromatographic standards were applied to a silica gel plate (Merck KGaA) using the CAMAG Automatic TLC Sampler 4 (CAMAG, Muttenz, Switzerland). Afterwards, the lipids were separated in a developing chamber using chloroform (Merck KgaA), methanol (Merck KgaA), ammonia 32\% (VWR Chemicals, Radnor, PA, USA) and lipid-free water (Carl Roth $\mathrm{GmbH}$ ) in a ratio of 161:75:5: 10 as mobile phase. To detect the internal standard TopFluor LPA, the plate was analyzed at $366 \mathrm{~nm}$ with the CAMAG TLC Visualizer 2 (CAMAG) and at $360 \mathrm{~nm}$ with the CAMAG TLC Scanner 4 (CAMAG) using a mercury lamp. Afterwards, lipids were derivatized with 10\% copper-II-sulfate (Merck KgaA), $8 \%$ phosphoric acid (Carl Roth $\mathrm{GmbH}$ ) and 5\% methanol (Merck KgaA) using the CAMAG Derivatizer (CAMAG). To detect the lipid profile, the plate was heated at $120^{\circ} \mathrm{C}$ for $2 \mathrm{~h}[72,73]$ and finally visualized at $366 \mathrm{~nm}$ with the CAMAG visualizer and scanned with the TLC scanner at $360 \mathrm{~nm}$ using the deuterium lamp. Lipid profiles were analyzed using the VisionCats program 2.4 (CAMAG) and further processed with Adobe Photoshop CC 2017 and Adobe Illustrator CC 2017 (Adobe, Inc., San José, CA, USA).

\subsection{Mass Spectrometry}

Lipids were extracted as previously described [74]. Briefly, tissues were homogenized in $1 \mathrm{~mL}$ $\mathrm{H}_{2} \mathrm{O}$ using the Stomacher microBiomaster homogenizer (Seward, Worthing, UK). After addition of the internal standard (30-pmol C17-lysophosphatidylcholine (C17-LPC), 30-pmol C15-ceramide (C15-Cer), 30-pmol C17-sphingosine (C17-Sph), 10-pmol C17-sphingosine-1-phosphate (C17-S1P), all from Avanti Polar Lipids, Alabaster, AL, USA), $200 \mu \mathrm{L}$ 6-N HCl, $1 \mathrm{ml}$ methanol and $2 \mathrm{~mL} \mathrm{CHCl}_{3}$ in glass centrifuge tubes, samples were vigorously vortexed for $10 \mathrm{~min}$. After centrifugation at $1900 \times g$, the lower $\mathrm{CHCl}_{3}$ phase was collected. Extraction was repeated with an additional $2 \mathrm{~mL} \mathrm{CHCl} 3$ and the two $\mathrm{CHCl}_{3}$ phases were combined and evaporated using the SpeedVac RVC 2-18 Cdplus (Christ, Osterode, Germany). Samples were resuspended in $100 \mu \mathrm{L}$ methanol/ $\mathrm{CHCl}_{3}(4: 1 v / v)$ and analyzed using the Prominence high-performance liquid chromatography (HPLC) system and the LCMS-8050 mass spectrometer (Shimadzu, Duisburg, Germany). Lipids were separated on a $2.1 \times 150$-mm Kinetex reversed-phase C-18 column with 2.6- $\mu \mathrm{m}$ particle size (Phenomenex, Aschaffenburg, Germany) with two separate programs at $50{ }^{\circ} \mathrm{C}$ oven temperature: sphingomyelin and sphingosine-1-phosphate were separated with the following program: Start with $80 \%$ mobile phase A $(0.1 \%$ formic acid in $\mathrm{H}_{2} \mathrm{O}$ ) and $20 \%$ mobile phase B (50\% acetonitrile, 50\% 2-propanol), $2 \mathrm{~min} 20 \% \mathrm{~B}, 4 \mathrm{~min} 40 \% \mathrm{~B}, 4 \mathrm{~min}$ 
B curve $-3,50 \min 92.5 \%$ B, $52 \min 100 \%$ B, $70 \min 100 \%$ B, $70.1 \mathrm{~min} 20 \%$ B, 80 min $20 \%$ B, flow rate $150 \mu \mathrm{L} / \mathrm{min}$. Ceramides and sphingosine were separated with the following program: Start with $90 \%$ mobile phase $\mathrm{A}\left(0.1 \%\right.$ formic acid in $\left.\mathrm{H}_{2} \mathrm{O}\right)$ and $10 \%$ mobile phase $\mathrm{B}$ (acetonitrile), $10 \mathrm{~min} 25 \%$ B, $20 \min 35 \%$ B, 40 min 75\% B, $40.1 \mathrm{~min} 95 \%$ B, 70 min 95\% B, 70.1 min 10\% B, 80 min 10\% B, flow rate $200 \mu \mathrm{L} / \mathrm{min}$. Mass spectrometry was carried out in MRM mode under optimized conditions with the electrospray ionization (ESI) source for sphingomyelin and sphingosine-1-phosphate and the atmospheric pressure chemical ionization (APCI) source for ceramide and sphingosine. Mass transitions were as follows: C17-LPC $m / z$ 510/184, C15-Cer $m / z$ 524/264, C17-Sph $m / z$ 286/268, C17-S1P $m / z 366 / 250$, Sph $m / z$ 300/286 and S1P $m / z$ 380/264. For the remaining analytes, the following mass fragments were quantified: ceramides, monohexosyl ceramides and lactosylceramides: $\mathrm{m} / \mathrm{z} 264$, dihydroceramides and monohexosyl dihydroceramides: $\mathrm{m} / \mathrm{z} 266$ and sphingomyelin: $\mathrm{m} / \mathrm{z} 184$. Data analysis was performed using LabSolutions 5.97 and LabSolutions Insight 3.1 (Shimadzu).

\subsection{Preparation of Mouse Primary Cells}

To analyze cell-specific mRNA expression levels of S1prs primary astrocytes, microglia, neurons and mature oligodendrocytes were prepared. For this, timed-pregnant and postnatal C57/BL6 and $\mathrm{BALB} / \mathrm{c}$ mice were collected at defined times (morning of vaginal plug was considered as embryonic day 0 (E0) for preparation of primary cells). Astrocyte and microglia preparation were performed using cerebra from mice at P1-3, following the previously described protocol of Klar et al. [75]. Serum-free preparation of mouse cortical primary neurons was performed with E18 ( \pm 0.5 days) mouse embryos as previously described by Brewer et al. [76] and Klar et al. [75]. Mature oligodendrocytes were prepared according to an adapted protocol of Chen et al. [77] and Suckau et al. [78] using cerebra from pups at P5. Purity of primary cell preparation was proven with cell-type-specific markers using qRT-PCR (Figure S4).

\subsection{Preparation and Cultivation of NPC1-Deficient Skin Fibroblasts Derived from Patients}

Written informed consent was obtained from each patient after counseling and explanation of possible consequences of the study. The study adhered to the tenets of the Declaration of Helsinki and was approved by the local medical ethics committee (Hannover Medical School, Germany (2576-2015) and Faculty of Medicine and Health Sciences at the Carl-von-Ossietzky University Oldenburg, Germany (2018-097)). Patients are siblings and both diagnosed by Morbus Niemann-Pick type C1 (NPC, OMIM257220). Molecular genetic testing of all 25 exons of the Npc1 gene (NM_000271.5) detected the homozygous sequence variant c.3182T >C (p.I1061 T), known to cause NPC1 in humans [21,79]. The siblings (sibling 1:26 years, sibling 2:24 years) were diagnosed at the age of twelve, showing to date symptoms like vertical gaze palsy, splenomegaly and progressive ataxia with pyramidal and extrapyramidal signs (Figure 6). Currently, sibling 2 is less affected than sibling 1 . Treatment of both patients with $3 \times 200 \mathrm{mg}$ miglustat started immediately after diagnosis. For further experiments, fibroblasts from both patients were prepared with the following procedure: After local anesthesia, a 2-3 mm skin biopsy sample from the inner arm area of each patient and control was obtained and cultured as previously described by Villegas et al. [80]. In brief, skin biopsies were transferred to minimum essential medium (MEM) with 20\% fetal bovine serum (FBS), $1.3 \%$ L-glutamine and $0.8 \%$ antibiotic-antimycotic (all from BioWest, Nuaillé, France). Biopsies were cut into pieces of approximately 1 to $2 \mathrm{~mm}^{2}$ and transferred to a sterile $75-\mathrm{cm}^{2}$ culture flask. The skin explants were briefly left to air dry and to attach to the bottom of the culture flasks. Then culture medium was added and the skin explants cultured for 7 to 14 days at $37{ }^{\circ} \mathrm{C}$ and $5 \% \mathrm{CO}_{2}$. After primary fibroblasts reached confluency of $50 \%$ to $75 \%$, cells were trypsinized and transferred to a new $75 \mathrm{~cm}^{2}$ flask for maintenance and experiments [80,81]. After the splitting process, 1, 5, 10 and 15 (p1, p5, p10, p15) RNA was extracted from about 500,000 cells for further qRT-PCR analyses. To verify the cholesterol accumulation, filipin staining was performed (Figure S5). Due to the lack of fibroblasts from healthy family members, fibroblasts from an apparently healthy individual (GM08398) obtained from Coriell 
Institute for Medical Research (Camden, NJ, USA) were used as a control for filipin staining. Fibroblasts were cultured in high glucose Dulbecco's modified Eagle's medium (DMEM) + GlutaMAX ${ }^{\mathrm{TM}}$-I (Life technologies/Gibco, Carlsbad, CA, USA), supplemented with 10\% FBS (Life technologies/Gibco) and $1 \%$ penicillin/streptomycin (Thermo Fisher Scientific, Schwerte, Germany) at $37^{\circ} \mathrm{C}$ and $5 \% \mathrm{CO}_{2}$.

\subsection{Derivation of Neuronal Cells from Human Induced Pluripotent Stem Cells (iPSCs)}

Human iPSCs were differentiated into a mixed culture of neurons and glia cells. Reprogramming of NPC1 patient-specific fibroblasts, carrying the Npc1 homozygous mutation c.3182 T>C, [p.I1061T] (GM18453, Coriell Institute for Medical Research) and fibroblasts of an apparently healthy control individual (GM05659, Coriell Institute for Medical Research), is described in detail in Peter et al. [82] and Trilck et al. [83], respectively. Neural differentiation of iPSCs was started by induction of the formation of neural rosettes. Once neural rosettes had spontaneously formed, neural progenitor cells were isolated using magnetic beads coated with antibodies against the marker of the neural lineage PSA-NCAM (Miltenyi Biotec, Bergisch Gladbach, Germany). The neural progenitor cells obtained were expanded and maintained in proliferation medium containing DMEM (Thermo Fisher Scientific), 40\% DMEM/F-12 (Thermo Fisher Scientific), 1X B27 (Thermo Fisher Scientific), 0.5\% penicillin/streptomycin (Thermo Fisher Scientific), 20-ng/mL basic fibroblast growth factor (FGF2, Amsbio, Abingdon, United Kingdom), 20-ng/mL epidermal growth factor (EGF, PeproTech, Hamburg, Germany). Terminal differentiation of neural progenitor cells was initiated by using differentiation medium containing DMEM, $40 \%$ DMEM/F-12, 1X B27, 0.5\% penicillin/streptomycin, which was changed every 4 days over a period of 40 days. For detailed protocols see Peter et al. [82] and Trilck et al. [83].

\subsection{RNA Extraction and cDNA Synthesis}

RNA was extracted from the following samples: brain tissue of sham-treated and treated $\mathrm{Npc1}^{+/+}$ and $\mathrm{Npc1}^{--}$mice, mouse primary cells, NPC1 patient-specific fibroblasts (sibling 1, sibling 2, GM18453) and fibroblasts of an apparently healthy individual (GM05659). Samples were homogenized with TRIzol reagent in accordance with the manufacturer's recommendation (Thermo Fisher Scientific, Waltham, MA, USA). Brain tissue was further homogenized mechanically using a syringe and needle. The further extraction process was performed according to the manufacturer's protocol. Isolated RNA was dissolved in an appropriate amount of ultrapure water. The RNA concentration was determined by measuring the absorbance at $260 \mathrm{~nm}$ with the BioSpectrometer basic (Eppendorf). RNA samples were stored at $-80{ }^{\circ} \mathrm{C}$ until further use. cDNA synthesis was performed using the high-capacity cDNA reverse transcription kit (Thermo Fisher Scientific). The 2-5 $\mu \mathrm{g}$ RNA was transcribed to cDNA at a final concentration of $0.1 \mu \mathrm{g} / \mu \mathrm{L}$. Control reactions were performed without MultiScribe reverse transcriptase (Thermo Fisher Scientific). cDNA was stored at $-20^{\circ} \mathrm{C}$. The quality of the cDNA was proven via PCR analysis with $A c t b$ primers: $\mathrm{ms} A c t b 5^{\prime}$ - cac agc tga gag gga aat cgt gcg tga $-3^{\prime}$ and $5^{\prime}$ tgc ggt gca cga tgg agg ggc cgg act - $3^{\prime}, \mathrm{hm} A c t b: 5^{\prime}$ - ccg agc ggg aaa tcg tgc gtg a $-3^{\prime}$ and $5^{\prime}$ - ggg ccg gac tcg tca tac tcc $\mathrm{t}-3^{\prime}$. The following thermal cycling parameters were used: 1 cycle with $95^{\circ} \mathrm{C}$ for $2 \mathrm{~min}$; 30 cycles with $95^{\circ} \mathrm{C}$ for $30 \mathrm{~s}, 68^{\circ} \mathrm{C}$ (hm Actb primers)/ $70{ }^{\circ} \mathrm{C}$ (ms Actb primers) for $30 \mathrm{~s}$ and $72{ }^{\circ} \mathrm{C}$ for 1 min; 1 cycle with $72{ }^{\circ} \mathrm{C}$ for 5 min. cDNA was subsequently used for qRT-PCR analyses.

\subsection{Quantitative Real-Time PCR ( $q R T$-PCR)}

qRT-PCR analysis was performed to detect S1pr1-5 mRNA expression in different brain regions of sham-treated and treated $\mathrm{Npcl}^{+/+}$and $\mathrm{Npc1}^{--}$mice (Figure 3), in mouse primary cells (Figure S4), NPC1 patient-specific fibroblasts (sibling 1 and sibling 2 shown in Figure 6, GM18453 shown in Figure S6,) and fibroblasts of an apparently healthy individual (GM05659 shown in Figure S6). Furthermore, qRT-PCR analysis was also used to check the purity of the prepared primary cells using specific cell markers shown in Figure S4 (Gfap for astrocytes, Iba1 for Microglia, Tuj1 for neurons, Ng2 for immature oligodendrocytes and Mbp for mature oligodendrocytes). The TaqMan ${ }^{\circledR}$ Fast Universal PCR Master Mix (2X), No AmpErase ${ }^{\circledR}$ UNG (Thermo Fisher Scientific) was used for qRT-PCR. According 
to the manufacturer's protocol, each reaction contained $100 \mathrm{ng}$ cDNA, $1 \mu \mathrm{L}$ of appropriate TaqMan ${ }^{\circledR}$ expression assay (listed in Table S1A, Thermo Fisher Scientific), $9 \mu \mathrm{L}$ ultrapure water and $10 \mu \mathrm{L}$ TaqMan ${ }^{\circledR}$ Fast Universal PCR Master Mix (2X), No AmpErase ${ }^{\circledR}$ UNG. All TaqMan ${ }^{\circledR}$ expression assays consists of a TaqMan ${ }^{\mathrm{TM}}$ Probe $(5 \mu \mathrm{M})$, a forward primer $(18 \mu \mathrm{M})$ and a reverse primer $(18$ $\mu \mathrm{M})$. The TaqMan ${ }^{\mathrm{TM}}$ Probe is labeled with the reporter dye FAM (6-carboxyfluorescein) at the $5^{\prime}$ - end and with MGB (minor groove binder) attached to a non-fluorescent quencher (NFQ) at the $3^{\prime}$ - end. The following thermal cycling parameters were used: $95^{\circ} \mathrm{C}$ for $20 \mathrm{~s}, 95^{\circ} \mathrm{C}$ for $1 \mathrm{~s}$ and $60^{\circ} \mathrm{C}$ for $20 \mathrm{~s}$ for 45 cycles. qRT-PCR was carried out at the 7900 HT Fast real-time PCR System using SDS 2.3 software (Applied Biosystems, Foster City, CA, USA), the ViiA 7 real-time PCR System using the QuantStudio real-time PCR software 1.2. (Thermo Fisher Scientific) or on the CFX96 Touch $^{\mathrm{TM}}$ real-time PCR detection system using CFX Manager Software 3.1 (Bio-Rad Laboratories, Hercules, CA, USA). Expression data were normalized to Ppia, $\beta$-Actin and/or Gapdh, that were proven as useful reference genes for qRT-PCR [84-86]. To analyze the relative change in mRNA expression, the $2^{-\Delta C t}$ method was used [87]. For each reaction, two replicates were performed. All data show the mean $\pm \mathrm{SEM}$ of at least three independent experiments.

\subsection{Cloning of EGFP-Coupled mS1pr1-5 Constructs}

For HEK293H cell transfection and subsequent western blot analyses, the following expression plasmids were generated: pEGFP-N1-mS1pr1, pEGFP-N1-mS1pr2, pEGFP-N1-mS1pr3, pEGFP-N1-mS1pr4 and pEGFP-N1-mS1pr5. mS1pr1 cDNA (GenBank accession no: NM_007901) was subcloned from DDK-Myc-tagged pCMV6-entry (MR205968, OriGene, Rockville, MD, USA) into pCR $^{\text {TM} 2.1-T O P O ~}{ }^{\text {TM }}$ Vector (Thermo Fisher Scientific, Waltham, MA, USA) by PCR amplification using oligonucleotides (synthesized from Eurofins genomics, Ebersberg, Germany) to insert restriction sites instead of the stop codon (listed in Table S1B). The PCR product was purified with the QIAEX gel extraction kit (Qiagen, Hilden, Germany). mS1pr2 ORF, mS1pr3 ORF, mS1pr4 ORF and mS1pr5 ORF (GenBank accession no: mS1pr2, NM_010333; mS1pr3, NM_010101; mS1pr4, NM_010102; mS1pr5, NM_053190) were subcloned from pFLAG-CMVTM-1 expression vector (Sigma-Aldrich) into pCR $^{\mathrm{TM}} 2.1-\mathrm{TOPO}^{\mathrm{TM}}$ Vector in the same way. Afterwards, all S1 pr fragments were cloned into the pGFP-N1 expression vector (Clontech Laboratories, Inc, Mountain View, CA, USA) using the following restriction enzymes (Table S1B): mS1pr1/mS1pr3/mS1pr5: BamHI, HindIII; mS1pr2: EcoRI, BamHI; mS1pr4: HindIII, PstI. Inserted S1pr1-5 cDNA sequences were analyzed by digestion with the respective restriction enzymes (Figure S3A) and sequencing, conducted at Eurofins genomics.

\subsection{Cell Culture and Transfection of HEK293H Cells}

HEK293H cells were obtained from Thermo Fisher Scientific and routinely cultivated in DMEM (PAN-Biotech, Aidenbach, Germany) supplemented with 10\% FBS (PAN-Biotech), 2-mM glutamine (Merck KgaA) and 1-U/mL penicillin/streptomycin (PAN-Biotech) at $37{ }^{\circ} \mathrm{C}$ and $5 \%$ $\mathrm{CO}_{2}$. The following plasmids were used for transfection: pGFP-N1-mS1pr1, pGFP-N1-mS1pr2, pGFP-N1-mS1pr3, pGFP-N1-mS1pr4, pGFP-N1-mS1pr5. For immunocytochemistry, $1 \times 10^{5}$ HEK293H cells were seeded on $0.1-\mathrm{mg} / \mathrm{mL}$ poly L-lysine (PLL) coated coverslips in 12 well plates and cultivated $24 \mathrm{~h}$. Cells were transfected using DNA-calcium phosphate co-precipitation; $1 \mu \mathrm{g}$ plasmid, diluted in $25 \mu \mathrm{L}$ sterile water, $2.5 \mu \mathrm{L} \mathrm{CaCl}_{2}$ and $50 \mu \mathrm{L}$ HEPES buffer ( $\mathrm{pH} 7.05$ ) were mixed, added to the wells and incubated for about $20 \mathrm{~h}$. For protein analysis, $8 \times 10^{6}$ cells were seeded at a density of $3.5 \times 10^{4}$ cells $/ \mathrm{cm}^{2}$ in $10 \mathrm{~cm}$ petri dishes and cultivated $24 \mathrm{~h}$. Adherent cells were transfected with $80 \mu \mathrm{g}$ of respective plasmid DNA diluted in $1350 \mu \mathrm{L}$ water (cell culture grade), $150 \mu \mathrm{L} \mathrm{CaCl}_{2}(2.5 \mathrm{M})$ and 1348 $\mu \mathrm{L}$ HEPES buffer ( $\mathrm{pH} 7.05)$ and incubated for about $20 \mathrm{~h}$.

\subsection{Immunocytochemistry}

Transfected HEK293H cells were fixed with ice-cold 4\% paraformaldehyde (PFA, Merck KgaA) in 1x phosphate buffer saline (PBS) containing 15\% sucrose for $20 \mathrm{~min}$ at RT. Afterwards, cells were 
permeabilized with $0.1 \%$ Triton and $0.1 \%$ sodium citrate in $1 \times \mathrm{PBS}$ for $3 \mathrm{~min}$ at $4{ }^{\circ} \mathrm{C}$ and then incubated for $1 \mathrm{~h}$ at RT in $1 \mathrm{x}$ PBS with $10 \%$ fetal calf serum (FCS). Cells were then incubated overnight at $4{ }^{\circ} \mathrm{C}$ with monoclonal anti-GFP antibody (632380, Clontech Laboratories, Inc, Mountain View, CA, USA), diluted 1:2500 in 1x PBS with 5\% FCS. Then, goat anti mouse Alexa Fluor 488 conjugated secondary antibody (Invitrogen, Carlsbad, CA, USA), diluted 1:1000 in 1x PBS with 5\% FCS, 1\% bovine serum albumin (BSA) and $0.5-\mu \mathrm{g} / \mathrm{mL}$ DAPI was incubated for $90 \mathrm{~min}$ at RT. Finally, coverslips were mounted with Mowiol-DABCO Mounting medium (Carl Roth $\mathrm{GmbH}$ ) and used for microscopy (Figure S3B). Fluorescence images of HEK293H cells transfected with GFP-coupled mS1pr1-5 plasmids were captured with the confocal laser scanning microscope Leica TCS SP8 (Leica, Wetzlar, Germany) using the confocal software (Leica). Images were taken using a $63 \times$ objective (oil-immersion, $1.2 \mathrm{NA}$ ) with the $488-\mathrm{nm}$ line of an argon-ion laser. Adjustment of brightness and contrast were performed using ImageJ (NIH, Bethesda, MD, USA).

\subsection{Lysate Preparation}

For protein extraction of GFP-coupled S1PR1-5, transfected HEK293H cells were lysed in lysis buffer supplemented with $7 \times$ cOmplete protease inhibitor cocktail (Merck KgaA), 10× PhosStop (Merck $\mathrm{KgaA}$ ) and 1-mM phenylmethylsulfonyl fluoride (PMSF, Thermo Fisher Scientific) using the $\mu$ MACS GFP isolation kit (Miltenyi Biotec) according to the manufacturer's protocol.

Protein extraction of different brain regions of sham-treated and treated $\mathrm{Npc1}^{+/+}$and $\mathrm{Npc}^{-\gamma^{--}}$mice was performed adding $500 \mu \mathrm{L}$ lysis buffer (20-mM Tris, pH 7.5, 0.25-M sucrose, 1-mM EGTA, 5-mM EDTA supplemented with $7 \times$ cOmplete protease inhibitor cocktail, $10 \times$ PhosStop and 1-mM PMSF). Tissue was homogenized mechanically with a syringe and a needle $(0.60 \times 60 \mathrm{~mm} / 0.90 \times 70 \mathrm{~mm})$ and sonicated $3 \times 3 \mathrm{sec}$. Afterwards, the lysates were incubated on ice for $30 \mathrm{~min}$ and centrifuged at 10,000 $\times$ $g, 10 \mathrm{~min}$ at $4{ }^{\circ} \mathrm{C}$. The supernatant was transferred to another vial and stored at $-20^{\circ} \mathrm{C}$.

\subsection{Western Blot Analysis}

Purified protein lysates of GFP-coupled S1PR1-5 were used to verify S1PR3/S1PR5 antibody specificity (Figure S3C-D). To analyze changes of S1PR3 and S1PR5 protein expression in sham-treated and treated $\mathrm{Npcl}^{+/+}$and $\mathrm{Npc1}^{--}$mice protein extracts of the PC, FC, HC, CE and BS were prepared. Protein concentrations were determined using the Pierce BCA Protein Assay Kit (Thermo Fisher Scientific) according to the manufacturer's protocol. Western blot was performed according to Velmans et al. [88], Vierk et al. [89] and Meyer et al. [35] with slight modifications. Purified protein lysates of GFP-coupled S1PR1-5 and total protein lysates (30-60 $\mu \mathrm{g}$ ) of sham-treated and treated $\mathrm{Npc1}^{+/+}$and $\mathrm{Npc1}^{--}$mice were subjected to $10 \%$ or $12 \%$ sodium dodecyl sulfate polyacrylamide gel electrophoresis (SDS-PAGE) and subsequently transferred to a nitrocellulose membrane (Amersham Protran 0.45 NC, GE Healthcare, Boston, MA, USA). Blots were blocked for $1 \mathrm{~h}$ with $5 \%$ non-fat dry milk or $5 \%$ BSA diluted in Tris-buffered saline with $0.1 \%$ Tween ${ }^{\circledR} 20$ (TBST) or $5 \%$ BSA diluted in PBS with $0.1 \%$ Tween (PBST) and incubated overnight at $4{ }^{\circ} \mathrm{C}$ with the following antibodies: mouse anti-GFP (1:2500, 632380, Clontech Laboratories, Inc.), rabbit anti-S1PR3 (1:500, ab38324, Abcam, Cambridge, UK), rabbit anti-S1PR5 (1:1000; ab92994, Abcam) and rabbit anti-PPIA (1:4000; ab42408, Abcam). Secondary antibodies were sheep anti-mouse IgG (1:10,000; NA931, GE Healthcare, Boston, MA, USA) and donkey anti-rabbit IgG (1:10,000; NA934, GE Healthcare) conjugated to horseradish peroxidase in 5\% non-fat dry milk or 5\% BSA diluted in TBST or 5\% BSA diluted in PBST. After incubation for $1 \mathrm{~h}$ at RT proteins were detected with Clarity ${ }^{\mathrm{TM}}$ Western ECL Substrate (Bio-Rad Laboratories) using the ChemiDoc ${ }^{\mathrm{TM}}$ imaging system (Bio-Rad Laboratories) and analyzed and quantified by using ImageLab 6.0 software (Bio-Rad Laboratories). Due to unspecific bands occurring with the S1PR3 antibody, an additional S1PR3 blocking peptide experiment was conducted (Figure S3C). For this purpose, the S1PR3 antibody (1:150) was supplemented with 10x concentrated S1PR3 blocking peptide (synthesized by Thermo Fisher Scientific, dissolved in PBS) in 5\% BSA diluted in TBST and incubated overnight at $4{ }^{\circ} \mathrm{C}$ with agitation. A control reaction was carried out using PBS instead of S1PR3 blocking peptide. Analysis, 
quantification and adjustment of brightness and contrast were performed using Image Lab software 6.0 (Bio-Rad Laboratories). Quantified western blots show the average of 4 to 5 separate experiments $(n=4-5)$, each of them was reproduced 3 times $(N=3)$.

\subsection{Filipin Staining}

NPC1 patient-specific fibroblasts (passage 5 of primary fibroblasts from sibling 1 and sibling 2) and fibroblasts of an apparently healthy individual (control: GM08398) were seeded at a density of about 25,000 cells $/ \mathrm{cm}^{2}$ on PLL-coated coverslips and cultivated for $24 \mathrm{~h}$ at $37{ }^{\circ} \mathrm{C}$ and $5 \% \mathrm{CO}_{2}$. Afterwards, cells were fixed with 4\% PFA (Merck KgaA) dissolved in 1x PBS for 15 min at RT, washed 2 $\times 5 \mathrm{~min}$ in $1 \times$ PBS and stored in $0.02 \%$ sodium azide (NaN3) at $4{ }^{\circ} \mathrm{C}$. Cells were incubated in $0.1-\mathrm{mg} / \mathrm{mL}$ Filipin (Polysciences, Inc., Warrington, PA, USA) for 45 min, mounted with Mowiol-DABCO Mounting medium (Carl Roth $\mathrm{GmbH}$ ) and used for microscopy (Figure S5). Differential interference contrast (DIC) images and fluorescence images were captured using the IX83 inverted imaging system with a DP80 camera (Olympus, Shinjuku, Japan). Images were taken with a 60x UplanSApo (oil-immersion, $1.35 \mathrm{NA}$ ) objective using the Olympus cellSens software (Olympus). Background correction and adjustment of brightness and contrast were performed using Image (NIH, Bethesda, MD, USA).

\subsection{Immunohistochemical Analysis of the Corpus Callosum Diameter}

Sham-treated and treated $\mathrm{Npc1}^{+/+}$and $\mathrm{Npc1}^{--}$mice used to determine callosal diameter were deeply anesthetized with a mixture of $50 \mathrm{mg} / \mathrm{kg}$ body weight ketamine hydrochloride (BelaPharm $\mathrm{GmbH} \& \mathrm{Co}$. KG, Vechta, Germany) and $2 \mathrm{mg} / \mathrm{kg}$ xylazine hydrochloride (Rompun ${ }^{\circledR}$, Bayer HealthCare, Leverkusen, Germany). Following this, mice were perfused with $0.9 \%$ normal saline solution and $4 \%$ PFA dissolved in 0.1-M PBS. Animals were decapitated, the entire brain was dissected out and postfixed in $4 \%$ PFA for $24 \mathrm{~h}$ at $4{ }^{\circ} \mathrm{C}$. Then, $30-\mu \mathrm{m}$-thick coronal brain sections were cut using a vibratome (VT $1000 \mathrm{~S}$, Leica). Sections were mounted on Superfrost slides (R. Langenbrinck GmbH, Emmendingen, Germany) and dried overnight at $37^{\circ} \mathrm{C}$. Rehydration and antigen retrieval were achieved via microwave treatment (20 min at $800 \mathrm{~W}$; Samsung Electronics GmbH, Schwalbach am Taunus, Germany). CNPase was used as a marker for myelinated fibers. For CNPase staining, sections were rinsed and incubated in a solution ( $3 \%$ normal goat serum $+0.1 \%$ Triton X-100 in PBS) containing the primary CNPase polyclonal antibody (1:300, Thermo Fisher Scientific) at $4{ }^{\circ} \mathrm{C}$ overnight. Rinsing the sections with PBS was followed by the application of the secondary antibody (Alexa Fluor 488-conjugated AffiniPure Goat Anti-Rabbit IgG (1:400, Jackson ImmunoResearch Laboratories, Inc., West Grove, PA, USA) in a solution containing 3\% normal goat serum $+0.1 \%$ Triton X-100 in PBS for 60 minutes at RT. Thereafter, sections were rinsed with PBS, counterstained with 4',6-diamidino-2 phenylindole dihydrochloride (DAPI, 1:10.000, Sigma-Aldrich), washed in distilled water and embedded in Mowiol (Merck KGaA). The thickness of the corpus callosum in each serial coronal section (29 sections \pm 3 of each group) was measured using an Olympus BX63 microscope (Olympus) controlled by the Olympus cellSens software (Olympus). Thereafter, the mean thickness per mouse brain was calculated.

\subsection{Morphometric Analysis of the Diameter of the Corpus Callosum}

Six to nine mice of each group were deeply anesthetized with a mixture of $50 \mathrm{mg} / \mathrm{kg}$ body weight ketamine hydrochloride (BelaPharm GmbH \& Co. KG, Vechta, Germany) and $2 \mathrm{mg} / \mathrm{kg}$ xylazine hydrochloride (Rompun ${ }^{\circledR}$, Bayer HealthCare, Leverkusen, Germany). Following this, Bodian-fixed, paraffin-embedded brains were cut at $20 \mu \mathrm{m}$ thickness and Nissl-stained. The thickness of the corpus callosum was measured in coronal sections at its thickest portion, at the level of the medial habenulae (in sham-treated $\mathrm{Npc1}^{+/+}$mice at Bregma $-1.94 \mathrm{~mm}$ ).

\subsection{Statistical Analysis}

Statistical evaluation of the qRT-PCR (Figure 3) and the western blot analysis (Figure 4) of different brain regions in sham-treated and treated $\mathrm{Npc1}^{+/+}$and $\mathrm{Npc1}^{-/}$mice was carried out with 
a nonparametric Mann-Whitney $U$-test using SPSS statistics 22/24 (IBM, Chicago, IL, USA). Equally, this test was used for statistical analysis of patient-derived fibroblasts (Figure S6). Statistical analysis of the corpus callosum diameter was performed with GraphPad Prism 7 using one-way analysis of variance (ANOVA) followed by Bonferroni correction of multiple comparisons. All graphs and heat maps were created using GraphPad Prism 7 (GraphPad Software, San Diego, CA, USA). Data are given as mean \pm SEM and considered significant if $p \leq 0.05\left({ }^{*} p \leq 0.05,{ }^{* * *} p \leq 0.001\right)$.

\section{Conclusions}

Based on our molecular data, we assume that S1P metabolism plays an important role in NPC1 pathology, especially S1pr3 and S1pr5 seem to be involved. In contrast to the spleen, liver and the olfactory system the brain only shows weak protective treatment effects. However, side effects can be shown at the molecular level. Next to our mouse analysis, we showed that S1P metabolism is also involved in human NPC1 disease. Interestingly, expression analysis of S1prs in human fibroblasts and human iPSC-derived NPCs and NDCs showed the most prominent changes in S1pr5 expression. This strengthened the assumption that S1pr5 plays a role in the course of NPC1 disease. Nevertheless, we need more knowledge concerning differential regulation and dysregulation at the cellular and molecular level in NPC1 disease. This is crucial for a better understanding of the starting point and progress of the disease, to be able to generate more promising treatment protocols including new drugs.

Supplementary Materials: Supplementary materials can be found at http://www.mdpi.com/1422-0067/21/12/ 4502/s1.

Author Contributions: A.U.B. designed the study. A.G. and A.U.B. wrote the study with contributions from all other co-authors. A.W. provided transgenic NPC1 mice. A.G. and A.-M.N. supported the treatment of the animals. M.H.G. performed the mass spectrometric analyses, supported by S.M.C. providing the devices. F.H. and A.G. performed lipid extraction and HPTLC analysis. A.G. performed sample preparation and qRT-PCR analyses of S1prs; cloning experiments, HEK293H cell transfection, immunocytochemistry and western blot analysis of GFP-coupled S1PRs such as cultivation and filipin staining of fibroblast from NPC1-deficient siblings. A.G. provided confocal image acquisition, image editing and statistical analysis. F.Y. and J.L. prepared oligodendrocyte cultures. A.R. provide miglustat. D.H. and M.W. performed morphometric analysis of the corpus callosum. E.T. and O.v.B.u.H. performed immunohistochemical analysis of the corpus callosum diameter and following confocal microscopy. G.C.K. M.O.-L. and J.N. performed and provided preparation of skin biopsy samples of both siblings suffering NPC1 disease. J.N. provided qRT-PCR System. C.V. and M.J.F. performed cultivation and reprogramming and differentiation of patient-derived fibroblasts. N.B. supported evaluation and analysis of western blot analysis as well as image editing. All authors have read and agree to the published version of the manuscript.

Funding: This work was supported by the Impuls Forschung, Verbund Norddeutscher Universitäten (O.v.B.u.H. and A.U.B./ A.U.B. and M.J.F.) and by the Federal Ministry of Education and Research (BMBF; ZIK Septomics Research Center, Translational Septomics, award no. 03Z22JN12 to SC).

Acknowledgments: Authors gratefully thank Actelion Pharmaceuticals (Allschwil, Switzerland) for the gift of miglustat for experimental applications. Jennifer Sevecke-Rave and Robin Piecha are acknowledged for the excellent technical assistance. Further, the authors thank Mathias Lietz, Ulf Haase and Susann Lehmann for animal care such as Rike Dannenberg and Bettina Brokowski for preparation of primary cells and Maike Möller for cultivation of human patient-derived fibroblasts. Support from the Fluorescence Microscopy Service Unit, Carl von Ossietzky University of Oldenburg for the use of the imaging facilities is gratefully acknowledged. The authors thank Dirk Koczan for providing qRT-PCR systems and the expert help on that. Technical support in image acquisition and western blot analysis of Isabel Groß is gratefully acknowledged. The authors thank Leo Bronstein (Institute of Biostatistics and Clinical Research, University of Münster) for statistical support and stels-ol.de for providing English language support.

Conflicts of Interest: The authors declare no conflict of interest. 


\section{Abbreviations}

\begin{tabular}{|c|c|}
\hline Actb & $\beta$-Actin \\
\hline AU & Arbitrary units \\
\hline BS & Brain stem \\
\hline $\mathrm{CE}$ & Cerebellum \\
\hline Cer & Ceramides \\
\hline CTL & Cytotoxic T lymphocytes \\
\hline $\mathrm{DC}$ & Dihydro ceramides \\
\hline FC & Frontal cortex \\
\hline FTY720 & Fingolimod \\
\hline Gapdh & Glyceraldehyde-3-phosphate dehydrogenase \\
\hline $\mathrm{HC}$ & Hippocampus \\
\hline HPTLC & High-performance thin-layer chromatography \\
\hline $\mathrm{HP} \beta \mathrm{CD}$ & 2-hydroxypropyl- $\beta$-cyclodextrin \\
\hline iPSC & Induced pluripotent stem cell \\
\hline LC & Lactosylceramides \\
\hline LPA & Lysophosphatidic acid \\
\hline LPC & Lysophosphatidylcholine \\
\hline MC & Monohexosyl ceramides \\
\hline MDC & Monohexosyl dihydroceramides \\
\hline NDCs & Neuronal differentiated cells \\
\hline NPC1 & Niemann-Pick type C1 \\
\hline NPCs & Neural progenitor cells \\
\hline $\mathrm{P}$ & Postnatal \\
\hline $\mathrm{p}$ & Passage \\
\hline PC & Parieto-occipital cortex \\
\hline PCR & Polymerase chain reaction \\
\hline Ppia & Peptidylprolyl isomerase A \\
\hline qRT-PCR & Quantitative real-time polymerase chain reaction \\
\hline Rf & Retention factor \\
\hline S1P & Sphingosine-1-phosphate \\
\hline S1pr & Sphingosine-1-phosphate receptor \\
\hline SM & Sphingomyelin \\
\hline Sph & Sphingosine \\
\hline
\end{tabular}

\section{References}

1. Millat, G.; Bailo, N.; Molinero, S.; Rodriguez, C.; Chikh, K.; Vanier, M.T. Niemann-Pick C disease: Use of denaturing high performance liquid chromatography for the detection of NPC1 and NPC2 genetic variations and impact on management of patients and families. Mol. Genet. Metab. 2005, 86, 220-232. [CrossRef] [PubMed]

2. Vanier, M.T. Niemann-Pick disease type C. Orphanet J. Rare Dis. 2010, 5, 16. [CrossRef] [PubMed]

3. Scott, C.; Ioannou, Y.A. The NPC1 protein: Structure implies function. Biochim. Biophys. Acta 2004, 1685, 8-13. [CrossRef] [PubMed]

4. Yu, X.H.; Jiang, N.; Yao, P.B.; Zheng, X.L.; Cayabyab, F.S.; Tang, C.K. NPC1, intracellular cholesterol trafficking and atherosclerosis. Clin. Chim. Acta 2014, 429, 69-75. [CrossRef]

5. Vanier, M.T. Niemann-Pick C disease: History, current research topics, biological and molecular diagnosis. Arch. Pediatr. 2010, 17 (Suppl. 2), S41-S44. [CrossRef]

6. Lloyd-Evans, E.; Platt, F.M. Lipids on trial: The search for the offending metabolite in Niemann-Pick type C disease. Traffic 2010, 11, 419-428. [CrossRef]

7. Carstea, E.D.; Morris, J.A.; Coleman, K.G.; Loftus, S.K.; Zhang, D.; Cummings, C.; Gu, J.; Rosenfeld, M.A.; Pavan, W.J.; Krizman, D.B.; et al. Niemann-Pick C1 disease gene: Homology to mediators of cholesterol homeostasis. Science 1997, 277, 228-231. [CrossRef] 
8. Garver, W.S.; Francis, G.A.; Jelinek, D.; Shepherd, G.; Flynn, J.; Castro, G.; Walsh Vockley, C.; Coppock, D.L.; Pettit, K.M.; Heidenreich, R.A.; et al. The National Niemann-Pick C1 disease database: Report of clinical features and health problems. Am. J. Med. Genet. A 2007, 143a, 1204-1211. [CrossRef]

9. Spiegel, R.; Raas-Rothschild, A.; Reish, O.; Regev, M.; Meiner, V.; Bargal, R.; Sury, V.; Meir, K.; Nadjari, M.; Hermann, G.; et al. The clinical spectrum of fetal Niemann-Pick type C. Am. J. Med. Genet. A 2009, 149a, 446-450. [CrossRef]

10. Vanier, M.T.; Millat, G. Niemann-Pick disease type C. Clin. Genet. 2003, 64, 269-281. [CrossRef]

11. Sarna, J.R.; Larouche, M.; Marzban, H.; Sillitoe, R.V.; Rancourt, D.E.; Hawkes, R. Patterned Purkinje cell degeneration in mouse models of Niemann-Pick type C disease. J. Comp. Neurol. 2003, 456, 279-291. [CrossRef] [PubMed]

12. Maass, F.; Petersen, J.; Hovakimyan, M.; Schmitt, O.; Witt, M.; Hawlitschka, A.; Lukas, J.; Rolfs, A.; Wree, A. Reduced cerebellar neurodegeneration after combined therapy with cyclodextrin/allopregnanolone and miglustat in NPC1: A mouse model of Niemann-Pick type C1 disease. J. Neurosci. Res. 2015, 93, 433-442. [CrossRef] [PubMed]

13. Tanaka, J.; Nakamura, H.; Miyawaki, S. Cerebellar involvement in murine sphingomyelinosis: A new model of Niemann-Pick disease. J. Neuropathol. Exp. Neurol. 1988, 47, 291-300. [CrossRef] [PubMed]

14. Elleder, M.; Jirasek, A.; Smid, F.; Ledvinova, J.; Besley, G.T. Niemann-Pick disease type C. Study on the nature of the cerebral storage process. Acta Neuropathol. 1985, 66, 325-336. [CrossRef]

15. Patterson, M.C.; Mengel, E.; Wijburg, F.A.; Muller, A.; Schwierin, B.; Drevon, H.; Vanier, M.T.; Pineda, M. Disease and patient characteristics in NP-C patients: Findings from an international disease registry. Orphanet J. Rare Dis. 2013, 8, 12. [CrossRef]

16. Piroth, T.; Boelmans, K.; Amtage, F.; Rijntjes, M.; Wierciochin, A.; Musacchio, T.; Weiller, C.; Volkmann, J.; Klebe, S. Adult-Onset Niemann-Pick Disease Type C: Rapid Treatment Initiation Advised but Early Diagnosis Remains Difficult. Front. Neurol. 2017, 8, 108. [CrossRef]

17. Feng, X.; Cozma, C.; Pantoom, S.; Hund, C.; Iwanov, K.; Petters, J.; Volkner, C.; Bauer, C.; Vogel, F.; Bauer, P.; et al. Detrmination of the Pathological Features of NPC1 Variants in a Cellular Complementation Teste. Int. J. Mol. Sci. 2019, 20, 5185. [CrossRef]

18. Bountouvi, E.; Papadopoulou, A.; Vanier, M.T.; Nyktari, G.; Kanellakis, S.; Michelakakis, H.; Dinopoulos, A. Novel NPC1 mutations with different segregation in two related Greek patients with Niemann-Pick type C disease: Molecular study in the extended pedigree and clinical correlations. BMC Med. Genet. 2017, 18, 51. [CrossRef]

19. Jahnova, H.; Dvorakova, L.; Vlaskova, H.; Hulkova, H.; Poupetova, H.; Hrebicek, M.; Jesina, P. Observational, retrospective study of a large cohort of patients with Niemann-Pick disease type $\mathrm{C}$ in the Czech Republic: A surprisingly stable diagnostic rate spanning almost 40 years. Orphanet J. Rare Dis. 2014, 9, 140. [CrossRef]

20. Park, W.D.; O'Brien, J.F.; Lundquist, P.A.; Kraft, D.L.; Vockley, C.W.; Karnes, P.S.; Patterson, M.C.; Snow, K. Identification of 58 novel mutations in Niemann-Pick disease type $\mathrm{C}$ : Correlation with biochemical phenotype and importance of PTC1-like domains in NPC1. Hum. Mutat. 2003, 22, 313-325. [CrossRef]

21. Millat, G.; Marcais, C.; Rafi, M.A.; Yamamoto, T.; Morris, J.A.; Pentchev, P.G.; Ohno, K.; Wenger, D.A.; Vanier, M.T. Niemann-Pick C1 disease: The I1061T substitution is a frequent mutant allele in patients of Western European descent and correlates with a classic juvenile phenotype. Am. J. Hum. Genet. 1999, 65, 1321-1329. [CrossRef] [PubMed]

22. Gelsthorpe, M.E.; Baumann, N.; Millard, E.; Gale, S.E.; Langmade, S.J.; Schaffer, J.E.; Ory, D.S. Niemann-Pick type C1 I1061T mutant encodes a functional protein that is selected for endoplasmic reticulum-associated degradation due to protein misfolding. J. Biol. Chem. 2008, 283, 8229-8236. [CrossRef] [PubMed]

23. Patterson, M.C.; Vecchio, D.; Prady, H.; Abel, L.; Wraith, J.E. Miglustat for treatment of Niemann-Pick C disease: A randomised controlled study. Lancet Neurol. 2007, 6, 765-772. [CrossRef]

24. Treiber, A.; Morand, O.; Clozel, M. The pharmacokinetics and tissue distribution of the glucosylceramide synthase inhibitor miglustat in the rat. Xenobiotica 2007, 37, 298-314. [CrossRef] [PubMed]

25. Pineda, M.; Walterfang, M.; Patterson, M.C. Miglustat in Niemann-Pick disease type C patients: A review. Orphanet J. Rare Dis. 2018, 13, 140. [CrossRef]

26. Platt, F.M.; Neises, G.R.; Dwek, R.A.; Butters, T.D. N-butyldeoxynojirimycin is a novel inhibitor of glycolipid biosynthesis. J. Biol. Chem. 1994, 269, 8362-8365. [PubMed] 
27. Zervas, M.; Somers, K.L.; Thrall, M.A.; Walkley, S.U. Critical role for glycosphingolipids in Niemann-Pick disease type C. Curr. Biol. 2001, 11, 1283-1287. [CrossRef]

28. Platt, F.M.; Jeyakumar, M. Substrate reduction therapy. Acta Paediatr. 2008, 97, 88-93. [CrossRef]

29. Liu, B.; Ramirez, C.M.; Miller, A.M.; Repa, J.J.; Turley, S.D.; Dietschy, J.M. Cyclodextrin overcomes the transport defect in nearly every organ of NPC1 mice leading to excretion of sequestered cholesterol as bile acid. J. Lipid Res. 2010, 51, 933-944. [CrossRef]

30. Davidson, C.D.; Ali, N.F.; Micsenyi, M.C.; Stephney, G.; Renault, S.; Dobrenis, K.; Ory, D.S.; Vanier, M.T.; Walkley, S.U. Chronic cyclodextrin treatment of murine Niemann-Pick C disease ameliorates neuronal cholesterol and glycosphingolipid storage and disease progression. PLoS ONE 2009, 4, e6951. [CrossRef]

31. Matsuo, M.; Togawa, M.; Hirabaru, K.; Mochinaga, S.; Narita, A.; Adachi, M.; Egashira, M.; Irie, T.; Ohno, K. Effects of cyclodextrin in two patients with Niemann-Pick Type C disease. Mol. Genet. Metab. 2013, 108, 76-81. [CrossRef] [PubMed]

32. Ramirez, C.M.; Liu, B.; Taylor, A.M.; Repa, J.J.; Burns, D.K.; Weinberg, A.G.; Turley, S.D.; Dietschy, J.M. Weekly cyclodextrin administration normalizes cholesterol metabolism in nearly every organ of the Niemann-Pick type C1 mouse and markedly prolongs life. Pediatr. Res. 2010, 68, 309-315. [CrossRef]

33. Crumling, M.A.; Liu, L.; Thomas, P.V.; Benson, J.; Kanicki, A.; Kabara, L.; Halsey, K.; Dolan, D.; Duncan, R.K. Hearing loss and hair cell death in mice given the cholesterol-chelating agent hydroxypropyl-beta-cyclodextrin. PLoS ONE 2012, 7, e53280. [CrossRef] [PubMed]

34. Bräuer, A.U.; Kuhla, A.; Holzmann, C.; Wree, A.; Witt, M. Current Challenges in Understanding the Cellular and Molecular Mechanisms in Niemann-Pick Disease Type C1. Int. J. Mol. Sci. 2019, 20, 4392. [CrossRef] [PubMed]

35. Meyer, A.; Gläser, A.; Bräuer, A.U.; Wree, A.; Strotmann, J.; Rolfs, A.; Witt, M. Olfactory Performance as an Indicator for Protective Treatment Effects in an Animal Model of Neurodegeneration. Front. Integr. Neurosci. 2018, 12, 35. [CrossRef] [PubMed]

36. Ebner, L.; Gläser, A.; Bräuer, A.; Witt, M.; Wree, A.; Rolfs, A.; Frank, M.; Vollmar, B.; Kuhla, A. Evaluation of Two Liver Treatment Strategies in a Mouse Model of Niemann-Pick-Disease Type C1. Int. J. Mol. Sci. 2018, 19, 972. [CrossRef]

37. Hovakimyan, M.; Maass, F.; Petersen, J.; Holzmann, C.; Witt, M.; Lukas, J.; Frech, M.J.; Hubner, R.; Rolfs, A.; Wree, A. Combined therapy with cyclodextrin/allopregnanolone and miglustat improves motor but not cognitive functions in Niemann-Pick Type C1 mice. Neuroscience 2013, 252, 201-211. [CrossRef] [PubMed]

38. Higashi, Y.; Murayama, S.; Pentchev, P.G.; Suzuki, K. Cerebellar degeneration in the Niemann-Pick type C mouse. Acta Neuropathol. 1993, 85, 175-184. [CrossRef]

39. Pentchev, P.G.; Gal, A.E.; Booth, A.D.; Omodeo-Sale, F.; Fouks, J.; Neumeyer, B.A.; Quirk, J.M.; Dawson, G.; Brady, R.O. A lysosomal storage disorder in mice characterized by a dual deficiency of sphingomyelinase and glucocerebrosidase. Biochim. Biophys. Acta 1980, 619, 669-679. [CrossRef]

40. Neßlauer, A.M.; Gläser, A.; Gräler, M.; Engelmann, R.; Müller-Hilke, B.; Frank, M.; Burstein, C.; Rolfs, A.; Neidhardt, J.; Wree, A.; et al. A therapy with miglustat, 2-hydroxypropyl- $\beta$-cyclodextrin and allopregnanolone restores splenic cholesterol homeostasis in Niemann-pick disease type C1. Lipids Health Dis. 2019, 18, 146. [CrossRef]

41. Meyer, A.; Wree, A.; Gunther, R.; Holzmann, C.; Schmitt, O.; Rolfs, A.; Witt, M. Increased Regenerative Capacity of the Olfactory Epithelium in Niemann-Pick Disease Type C1. Int. J. Mol. Sci. 2017, $18,777$. [CrossRef] [PubMed]

42. Lloyd-Evans, E.; Morgan, A.J.; He, X.; Smith, D.A.; Elliot-Smith, E.; Sillence, D.J.; Churchill, G.C.; Schuchman, E.H.; Galione, A.; Platt, F.M. Niemann-Pick disease type $\mathrm{C} 1$ is a sphingosine storage disease that causes deregulation of lysosomal calcium. Nat. Med. 2008, 14, 1247-1255. [CrossRef] [PubMed]

43. Speak, A.O.; Te Vruchte, D.; Davis, L.C.; Morgan, A.J.; Smith, D.A.; Yanjanin, N.M.; Simmons, L.; Hartung, R.; Runz, H.; Mengel, E.; et al. Altered distribution and function of natural killer cells in murine and human Niemann-Pick disease type C1. Blood 2014, 123, 51-60. [CrossRef] [PubMed]

44. Spiegel, S.; Milstien, S. The outs and the ins of sphingosine-1-phosphate in immunity. Nat. Rev. Immunol. 2011, 11, 403-415. [CrossRef]

45. Kluk, M.J.; Hla, T. Signaling of sphingosine-1-phosphate via the S1P/EDG-family of G-protein-coupled receptors. Biochim. Biophys. Acta 2002, 1582, 72-80. [CrossRef] 
46. Fan, M.; Sidhu, R.; Fujiwara, H.; Tortelli, B.; Zhang, J.; Davidson, C.; Walkley, S.U.; Bagel, J.H.; Vite, C.; Yanjanin, N.M.; et al. Identification of Niemann-Pick C1 disease biomarkers through sphingolipid profiling. J. Lipid Res. 2013, 54, 2800-2814. [CrossRef]

47. Chen, F.W.; Gordon, R.E.; Ioannou, Y.A. NPC1 late endosomes contain elevated levels of non-esterified ('free') fatty acids and an abnormally glycosylated form of the NPC2 protein. Biochem. J. 2005, 390 Pt 2, 549-561. [CrossRef]

48. Weintraub, H.; Abramovici, A.; Sandbank, U.; Pentchev, P.G.; Brady, R.O.; Sekine, M.; Suzuki, A.; Sela, B. Neurological mutation characterized by dysmyelination in NCTR-Balb/C mouse with lysosomal lipid storage disease. J. Neurochem. 1985, 45, 665-672. [CrossRef]

49. Palmeri, S.; Battisti, C.; Federico, A.; Guazzi, G.C. Hypoplasia of the corpus callosum in Niemann-Pick type C disease. Neuroradiology 1994, 36, 20-22. [CrossRef]

50. Dusaban, S.S.; Chun, J.; Rosen, H.; Purcell, N.H.; Brown, J.H. Sphingosine 1-phosphate receptor 3 and RhoA signaling mediate inflammatory gene expression in astrocytes. J. Neuroinflamm. 2017, 14, 111. [CrossRef]

51. German, D.C.; Liang, C.L.; Song, T.; Yazdani, U.; Xie, C.; Dietschy, J.M. Neurodegeneration in the Niemann-Pick C mouse: Glial involvement. Neuroscience 2002, 109, 437-450. [CrossRef]

52. Park, M.H.; Lee, J.Y.; Jeong, M.S.; Jang, H.S.; Endo, S.; Bae, J.S.; Jin, H.K. The role of Purkinje cell-derived VEGF in cerebellar astrogliosis in Niemann-Pick type C mice. BMB Rep. 2018, 51, 79-84. [CrossRef] [PubMed]

53. Jaillard, C.; Harrison, S.; Stankoff, B.; Aigrot, M.S.; Calver, A.R.; Duddy, G.; Walsh, F.S.; Pangalos, M.N.; Arimura, N.; Kaibuchi, K.; et al. Edg8/S1P5: An oligodendroglial receptor with dual function on process retraction and cell survival. J. Neurosci. 2005, 25, 1459-1469. [CrossRef] [PubMed]

54. Novgorodov, A.S.; El-Alwani, M.; Bielawski, J.; Obeid, L.M.; Gudz, T.I. Activation of sphingosine-1-phosphate receptor S1P5 inhibits oligodendrocyte progenitor migration. Faseb J. 2007, 21, 1503-1514. [CrossRef] [PubMed]

55. Cumings, J.N.; Goodwin, H. Sphingolopids and phospholipids of myelin in multiple sclerosis. Lancet 1968, 2, 664-665. [CrossRef]

56. Halmer, R.; Walter, S.; Fassbender, K. Sphingolipids: Important players in multiple sclerosis. Cell. Physiol. Biochem. 2014, 34, 111-118. [CrossRef]

57. Olsen, A.S.B.; Faergeman, N.J. Sphingolipids: Membrane microdomains in brain development, function and neurological diseases. Open Biol. 2017, 7, 170069. [CrossRef]

58. Karunakaran, I.; van Echten-Deckert, G. Sphingosine 1-phosphate-A double edged sword in the brain. Biochim. Biophys. Acta Biomembr. 2017, 1859 Pt B, 1573-1582. [CrossRef]

59. Newton, J.; Palladino, E.N.D.; Weigel, C.; Maceyka, M.; Gräler, M.H.; Senkal, C.E.; Enriz, R.D.; Marvanova, P.; Jampilek, J.; Lima, S.; et al. Targeting defective sphingosine kinase 1 in Niemann-Pick type C disease with an activator mitigates cholesterol accumulation. J. Biol. Chem. 2020. [CrossRef]

60. Martin, R.; Sospedra, M. Sphingosine-1 phosphate and central nervous system. Curr. Top. Microbiol. Immunol. 2014, 378, 149-170.

61. Fischer, I.; Alliod, C.; Martinier, N.; Newcombe, J.; Brana, C.; Pouly, S. Sphingosine kinase 1 and sphingosine 1-phosphate receptor 3 are functionally upregulated on astrocytes under pro-inflammatory conditions. PLoS ONE 2011, 6, e23905. [CrossRef]

62. Foster, C.A.; Mechtcheriakova, D.; Storch, M.K.; Balatoni, B.; Howard, L.M.; Bornancin, F.; Wlachos, A.; Sobanov, J.; Kinnunen, A.; Baumruker, T. FTY720 rescue therapy in the dark agouti rat model of experimental autoimmune encephalomyelitis: Expression of central nervous system genes and reversal of blood-brain-barrier damage. Brain Pathol. 2009, 19, 254-266. [CrossRef] [PubMed]

63. Edsall, L.C.; Spiegel, S. Enzymatic measurement of sphingosine 1-phosphate. Anal. Biochem. 1999, 272, 80-86. [CrossRef] [PubMed]

64. Wu, Y.P.; Mizugishi, K.; Bektas, M.; Sandhoff, R.; Proia, R.L. Sphingosine kinase 1/S1P receptor signaling axis controls glial proliferation in mice with Sandhoff disease. Hum. Mol. Genet. 2008, 17, 2257-2264. [CrossRef] [PubMed]

65. Ory, D.S.; Ottinger, E.A.; Farhat, N.Y.; King, K.A.; Jiang, X.; Weissfeld, L.; Berry-Kravis, E.; Davidson, C.D.; Bianconi, S.; Keener, L.A.; et al. Intrathecal 2-hydroxypropyl-beta-cyclodextrin decreases neurological disease progression in Niemann-Pick disease, type C1: A non-randomised, open-label, phase 1-2 trial. Lancet 2017, 390, 1758-1768. [CrossRef] 
66. Wraith, J.E.; Vecchio, D.; Jacklin, E.; Abel, L.; Chadha-Boreham, H.; Luzy, C.; Giorgino, R.; Patterson, M.C. Miglustat in adult and juvenile patients with Niemann-Pick disease type C: Long-term data from a clinical trial. Mol. Genet. Metab. 2010, 99, 351-357. [CrossRef] [PubMed]

67. Hait, N.C.; Allegood, J.; Maceyka, M.; Strub, G.M.; Harikumar, K.B.; Singh, S.K.; Luo, C.; Marmorstein, R.; Kordula, T.; Milstien, S.; et al. Regulation of histone acetylation in the nucleus by sphingosine-1-phosphate. Science 2009, 325, 1254-1257. [CrossRef] [PubMed]

68. Hait, N.C.; Wise, L.E.; Allegood, J.C.; O'Brien, M.; Avni, D.; Reeves, T.M.; Knapp, P.E.; Lu, J.; Luo, C.; Miles, M.F.; et al. Active, phosphorylated fingolimod inhibits histone deacetylases and facilitates fear extinction memory. Nat. Neurosci. 2014, 17, 971-980. [CrossRef]

69. Newton, J.; Hait, N.C.; Maceyka, M.; Colaco, A.; Maczis, M.; Wassif, C.A.; Cougnoux, A.; Porter, F.D.; Milstien, S.; Platt, N.; et al. FTY720/fingolimod increases NPC1 and NPC2 expression and reduces cholesterol and sphingolipid accumulation in Niemann-Pick type C mutant fibroblasts. Faseb J. 2017, 31, 1719-1730. [CrossRef]

70. Bligh, E.G.; Dyer, W.J. A rapid method of total lipid extraction and purification. Can. J. Biochem. Physiol. 1959, 37, 911-917. [CrossRef]

71. Moldoveanu, S.C. Solutions and challenges in sample preparation for chromatography. J. Chromatogr. Sci. 2004, 42, 1-14. [CrossRef] [PubMed]

72. Fewster, M.E.; Burns, B.J.; Mead, J.F. Quantitative densitometric thin-layer chromatography of lipids using copper acetate reagent. J. Chromatogr. 1969, 43, 120-126. [CrossRef]

73. Churchward, M.A.; Brandman, D.M.; Rogasevskaia, T.; Coorssen, J.R. Copper (II) sulfate charring for high sensitivity on-plate fluorescent detection of lipids and sterols: Quantitative analyses of the composition of functional secretory vesicles. J. Chem. Biol. 2008, 1, 79-87. [CrossRef] [PubMed]

74. Bode, C.; Gräler, M.H. Quantification of sphingosine-1-phosphate and related sphingolipids by liquid chromatography coupled to tandem mass spectrometry. Methods Mol. Biol. 2012, 874, 33-44. [PubMed]

75. Klar, M.; Fenske, P.; Vega, F.R.; Dame, C.; Bräuer, A.U. Transcription factor Yin-Yang 2 alters neuronal outgrowth in vitro. Cell Tissue Res. 2015, 362, 453-460. [CrossRef] [PubMed]

76. Brewer, G.J.; Torricelli, J.R.; Evege, E.K.; Price, P.J. Optimized survival of hippocampal neurons in B27-supplemented Neurobasal, a new serum-free medium combination. J. Neurosci. Res. 1993, 35, 567-576. [CrossRef]

77. Chen, Y.; Balasubramaniyan, V.; Peng, J.; Hurlock, E.C.; Tallquist, M.; Li, J.; Lu, Q.R. Isolation and culture of rat and mouse oligodendrocyte precursor cells. Nat. Protoc. 2007, 2, 1044-1051. [CrossRef]

78. Suckau, O.; Gross, I.; Schrotter, S.; Yang, F.; Luo, J.; Wree, A.; Chun, J.; Baska, D.; Baumgart, J.; Kano, K.; et al. LPA1, LPA2, LPA4, and LPA6 receptor expression during mouse brain development. Dev. Dyn. 2019, 248, 375-395. [CrossRef]

79. Yamamoto, T.; Nanba, E.; Ninomiya, H.; Higaki, K.; Taniguchi, M.; Zhang, H.; Akaboshi, S.; Watanabe, Y.; Takeshima, T.; Inui, K.; et al. NPC1 gene mutations in Japanese patients with Niemann-Pick disease type C. Hum. Genet. 1999, 105, 10-16.

80. Villegas, J.; McPhaul, M. Establishment and culture of human skin fibroblasts. Curr. Protoc. Mol. Biol. 2005, 71, 28-33. [CrossRef]

81. Glaus, E.; Schmid, F.; Da Costa, R.; Berger, W.; Neidhardt, J. Gene therapeutic approach using mutation-adapted U1 snRNA to correct a RPGR splice defect in patient-derived cells. Mol. Ther. 2011, 19, 936-941. [CrossRef] [PubMed]

82. Peter, F.; Trilck, M.; Rabenstein, M.; Rolfs, A.; Frech, M.J. Dataset in support of the generation of Niemann-Pick disease Type C1 patient-specific iPS cell lines carrying the novel NPC1 mutation c.1180T>C or the prevalent c.3182T>C mutation-Analysis of pluripotency and neuronal differentiation. Data Brief. 2017, 12, 123-131. [CrossRef] [PubMed]

83. Trilck, M.; Hubner, R.; Seibler, P.; Klein, C.; Rolfs, A.; Frech, M.J. Niemann-Pick type C1 patient-specific induced pluripotent stem cells display disease specific hallmarks. Orphanet J. Rare Dis. 2013, 8, 144. [CrossRef] [PubMed]

84. Kennedy, B.E.; LeBlanc, V.G.; Mailman, T.M.; Fice, D.; Burton, I.; Karakach, T.K.; Karten, B. Pre-symptomatic activation of antioxidant responses and alterations in glucose and pyruvate metabolism in Niemann-Pick Type C1-deficient murine brain. PLoS ONE 2013, 8, e82685. [CrossRef] 
85. Maulik, M.; Thinakaran, G.; Kar, S. Alterations in gene expression in mutant amyloid precursor protein transgenic mice lacking Niemann-Pick type C1 protein. PLoS ONE 2013, 8, e54605. [CrossRef]

86. Zampieri, S.; Bembi, B.; Rosso, N.; Filocamo, M.; Dardis, A. Treatment of Human Fibroblasts Carrying NPC1 Missense Mutations with MG132 Leads to an Improvement of Intracellular Cholesterol Trafficking. JIMD Rep. 2012, 2, 59-69.

87. Livak, K.J.; Schmittgen, T.D. Analysis of relative gene expression data using real-time quantitative PCR and the 2(-Delta Delta C(T)) Method. Methods 2001, 25, 402-408. [CrossRef]

88. Velmans, T.; Battefeld, A.; Geist, B.; Farres, A.S.; Strauss, U.; Bräuer, A.U. Plasticity-related gene 3 promotes neurite shaft protrusion. BMC Neurosci. 2013, 14, 36. [CrossRef]

89. Vierk, R.; Glassmeier, G.; Zhou, L.; Brandt, N.; Fester, L.; Dudzinski, D.; Wilkars, W.; Bender, R.A.; Lewerenz, M.; Gloger, S.; et al. Aromatase inhibition abolishes LTP generation in female but not in male mice. J. Neurosci. 2012, 32, 8116-8126. [CrossRef]

(C) 2020 by the authors. Licensee MDPI, Basel, Switzerland. This article is an open access article distributed under the terms and conditions of the Creative Commons Attribution (CC BY) license (http://creativecommons.org/licenses/by/4.0/). 